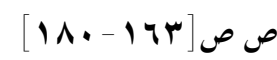

أثر تقلبات سعر الصرف على بعض متغيرات الاقتصاد الكلي(*) في عدد من الدول النامية متفيز

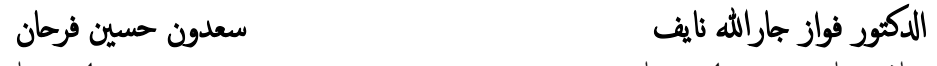

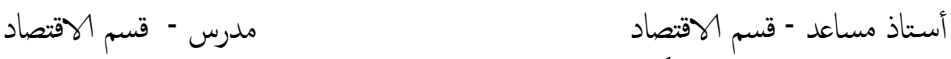

$$
\begin{aligned}
& \text { كلية الإدارة والاقتصاد - جامعة الموصل }
\end{aligned}
$$

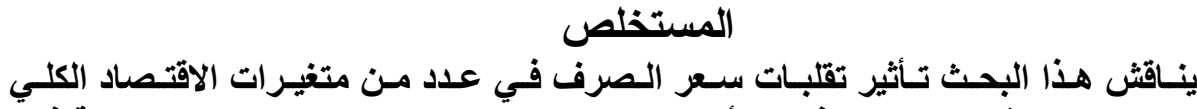

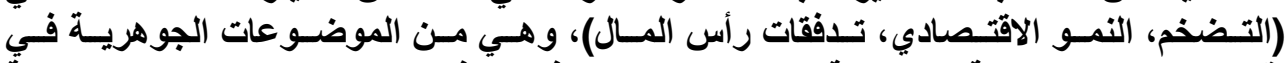

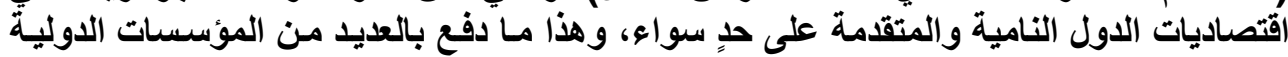

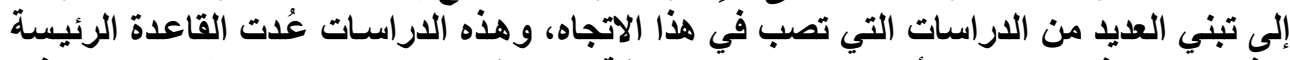

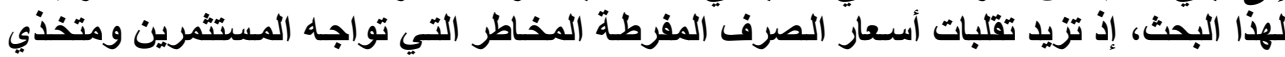

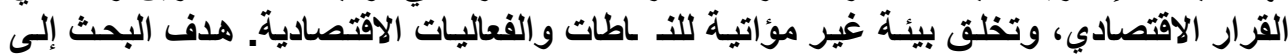

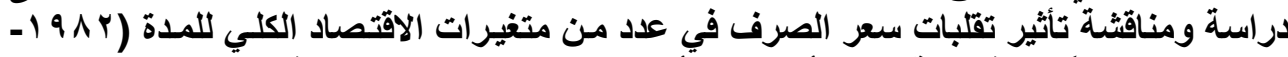

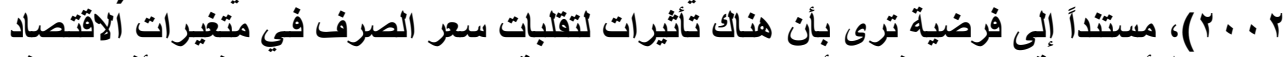

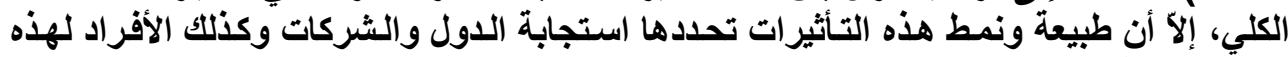

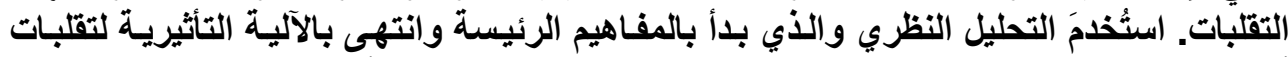

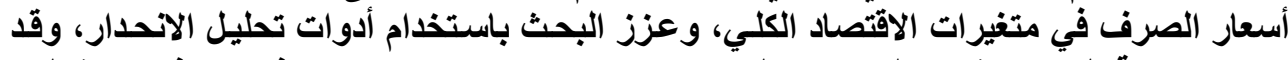

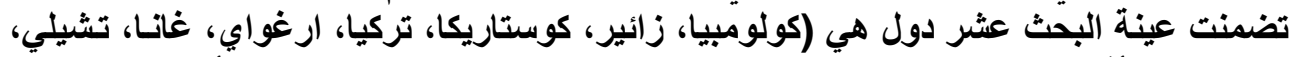

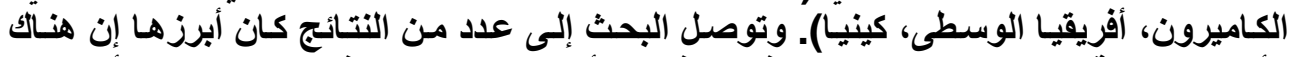

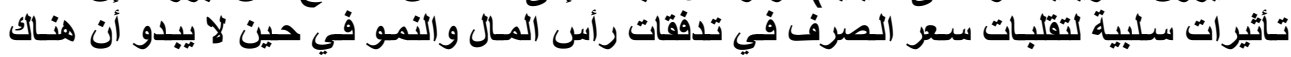
ارتباطات واسعة بين هذه التقلبات والتضخئر.

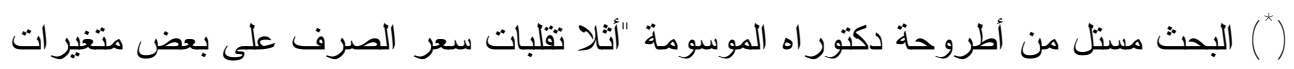

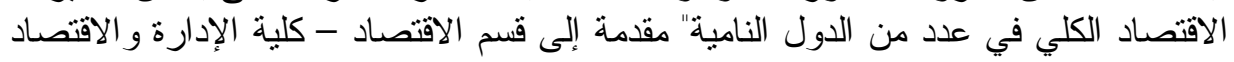

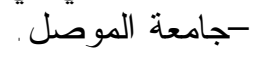

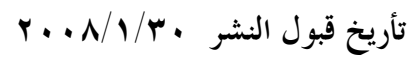

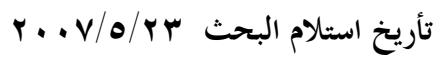




\title{
The Effect of Exchange Rate s' Fluctuations on Some Macroeconomic Variables in Developing Countries Numbers
}

\author{
Fawaz Jar allah Nayif (PhD) \\ Assistant Professor \\ Department of Economics \\ University of Mosul
}

\author{
Saadoon Hussian Farhan (PhD) \\ Lecturer \\ Department of Economics \\ University of Mosul
}

\begin{abstract}
This research discusses the effect of the exchange rate fluctuations in some macroeconomic variables (inflation, economic growth, private capital inflow). They are essential subjects in the economies of the developing and developed countries on the same side. This issue had led the International Organizations (like IMF) to adopt several studies which interest in this subject. These studies treated as the main basis of this research, because the excessive exchange rate fluctuations may increase the risks by which the investors and economic decision takers may face. This consequently may create unsuitable environment for economic activities. This research aims to study and discuss the effect of the exchange rate fluctuations in some macroeconomic variables for the period (1982 2002), via depending an assumption seeing that there is some effects for the exchange rate fluctuations on macroeconomic variables, but the nature and the style of these effects limiting it. The responding of the countries and companies, also the individuals for these fluctuations have been proposed. The research used two manners in analysis:

The first: The theoretical framework which had started by the main concepts and which finished by the affecting mechanism of the exchange rate fluctuations on macroeconomic variables.

The second: The quantitative framework, used in it the regression analysis, the research sample contained ten countries (Colombia, Zaire, Costa Rica, Turkey, Uruguay, Ghana, Chile, Cameron, Kenya, Central Africa). The research concluded some results, the most important result was: there is negative effects for the exchange rate fluctuations on capital inflow and the growth while it not seems that there is wide correlations between these fluctuations and inflation.
\end{abstract}

المقدمة

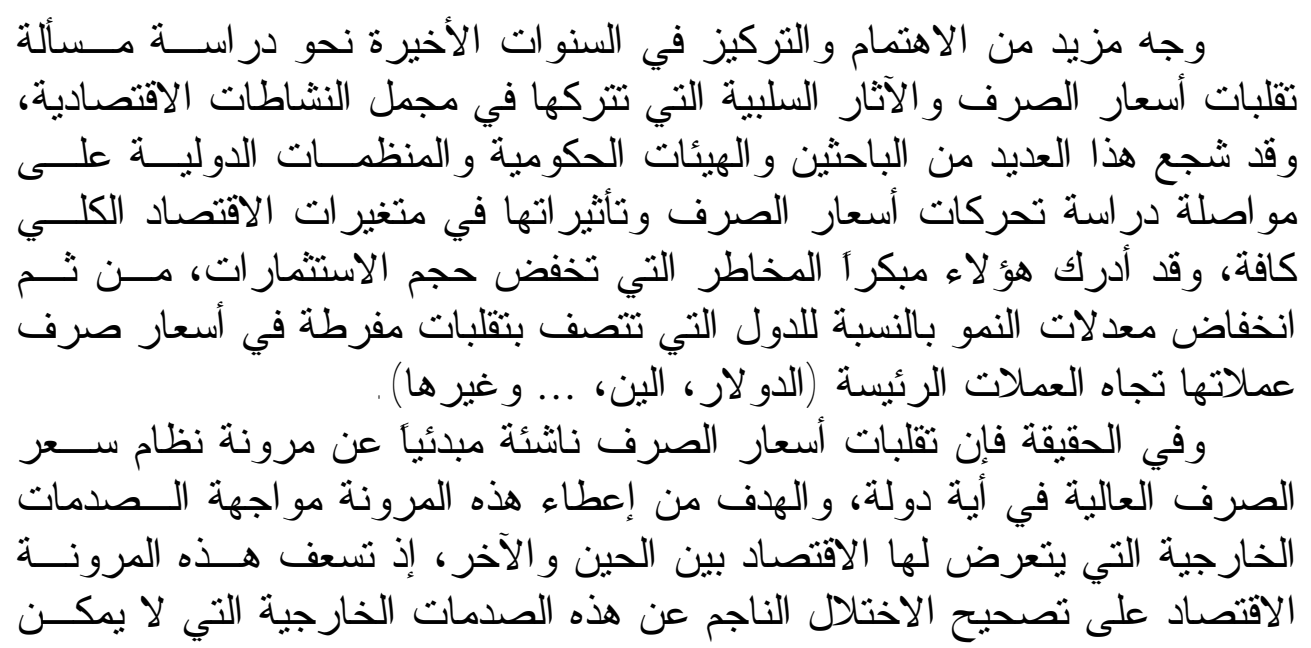




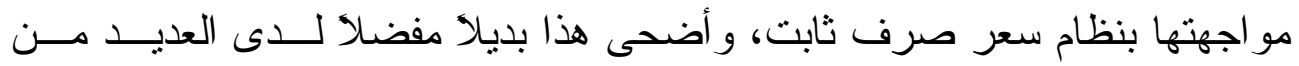

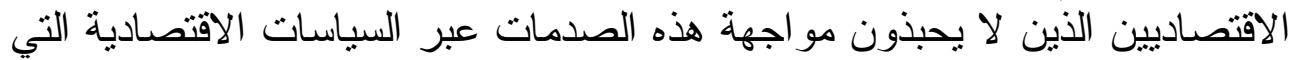

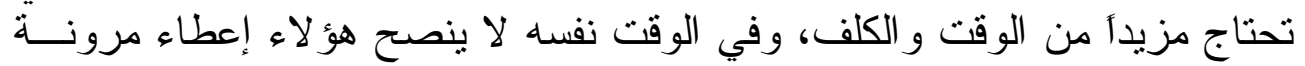

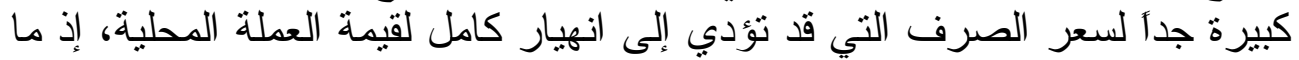

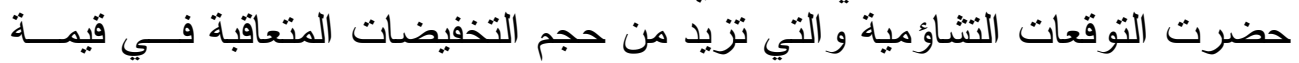
العملة المحلية.

\section{أهمية البحث}

تعد در اسة تقلبات سعر الصرف وتأثنير اتها مسألة مهمة لاقتصساد يبحث عـن

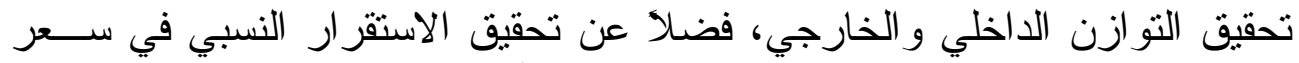

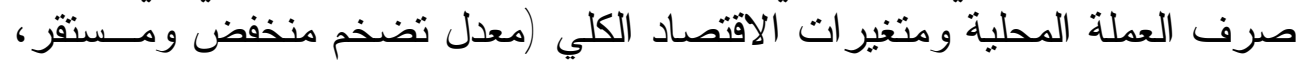
معدلات نمو مرتفعة ومستقرة) .

تخلق تقلبات أسعار الصرف المفرطة بيئة غير مؤاتية للنشاطات الاقتصادية،

مشكلة البحث إذ تصبح هذه النشاطات صعبة للغاية بحضور التقلبات المفرطة إذ تــدفع الأخيــرة

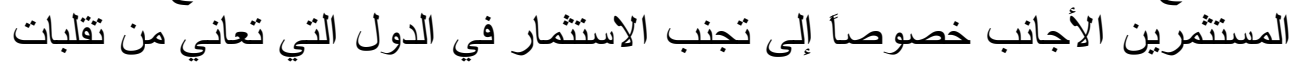
مفرطة في أسعار صرف عملاتها، ومن جهة أخرى تؤثز التقلبات في نمط الإني الإنتاج

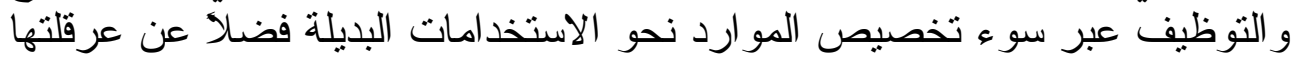
للجهود الر امية إلى زيادة معدلات لنو النمو .

هدف البحث يهدف البحث إلى در اسة ومناقثة تأثير ات تقلبات أسعار الصرف في عدد من الصن

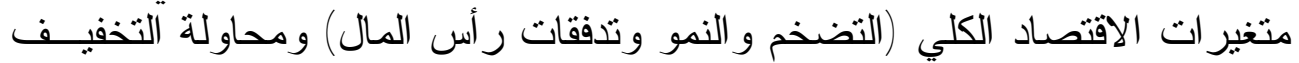
من آثار ها السلبية.

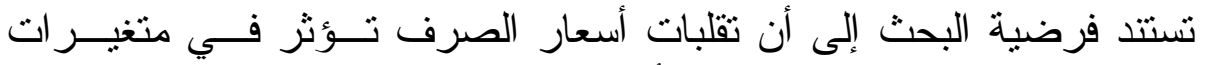

فرضية البحث الاقتصاد الكلي و ان طبيعة ونمط هذه التأثير ات تحددها استجابة الدول و الـشركات وكذللك الأفر اد لهذه التقلبات .

اعتمد البحث على الربط الوثيث بين جانبين : الأول الإطار النظـــري، الــــي

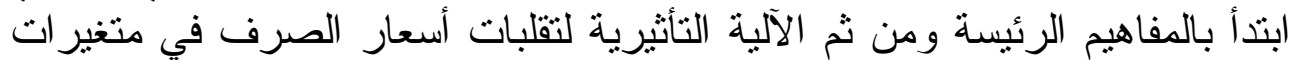

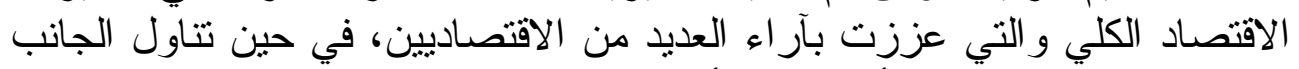

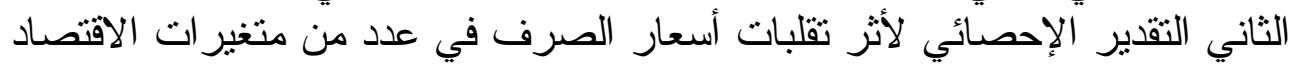




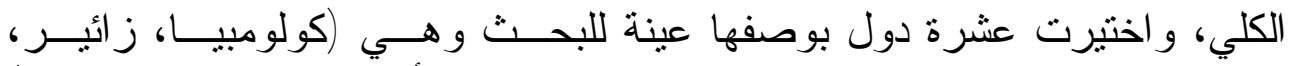

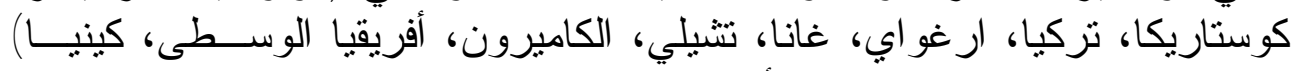

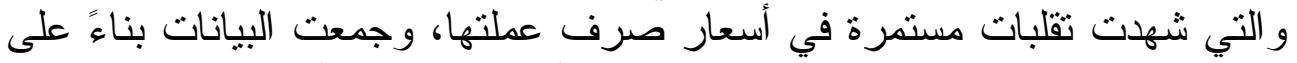

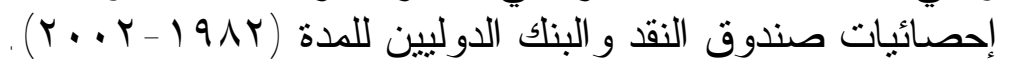

\section{المدخل النظري لاراسة سعر الصرف وكيفية قياسه

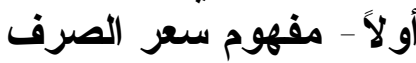

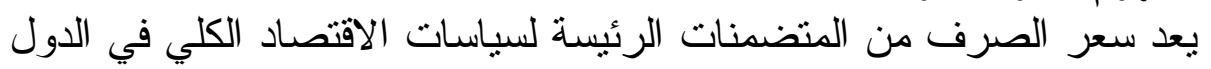

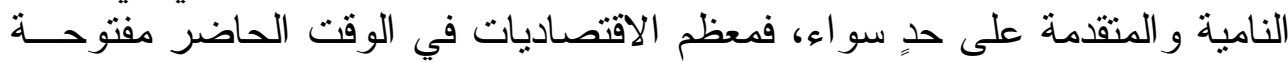

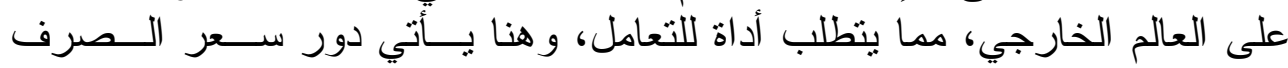

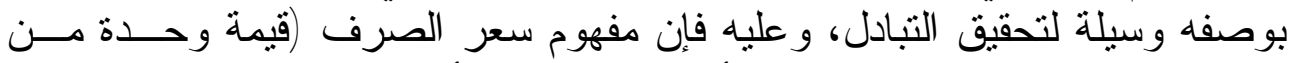

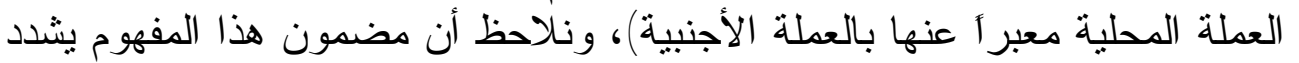

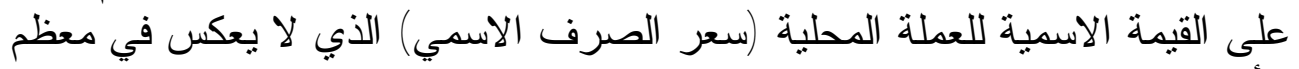

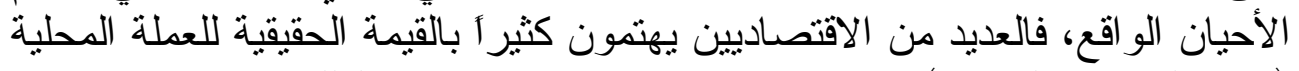

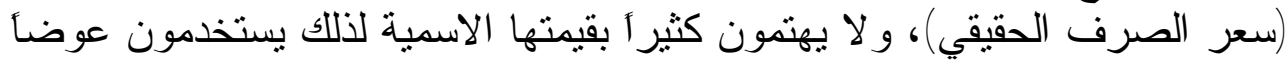
عنه سعر الصرف الحقيقي، ولان ثانياً - سعر الصرف الحقيقي

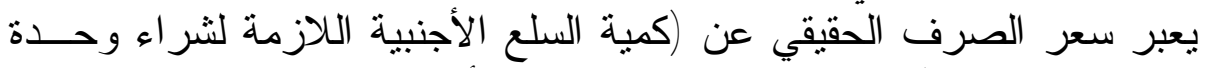
و احدة من السلع المحلية) ويحتسب رياضياً بالثكل الأتي:

$$
\mathrm{Exr}=\frac{P d o}{E n * P W}
$$

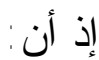

$$
\begin{aligned}
& \text { =Exr } \\
& \text { =En } \\
& \text { = Pdo } \\
& \text { = مستوى الأسعار الأجنبية = PW }
\end{aligned}
$$

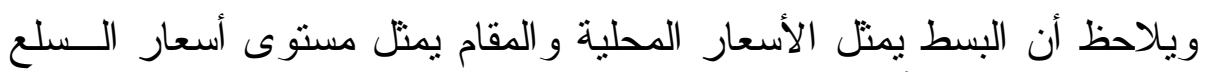

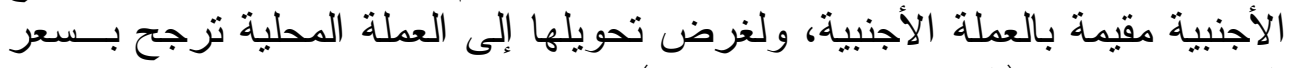

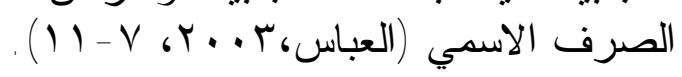




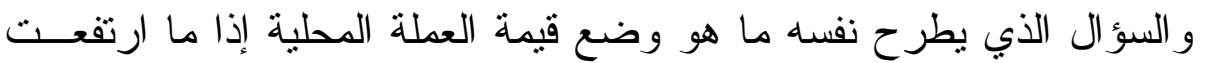

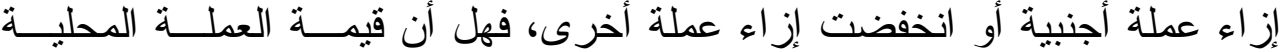

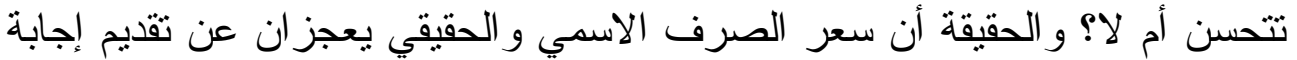

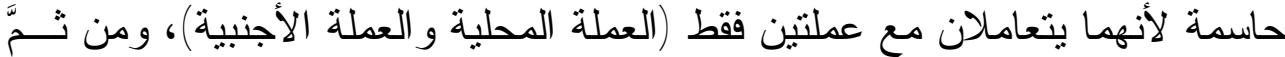

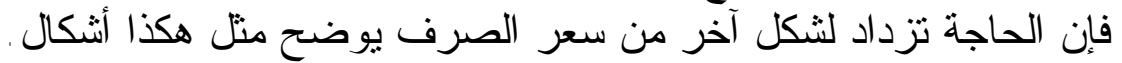

ويعبر عن سعر الصرف الإني الأسمي الثنائي مرجحأ بالأوزان التجارية الثنائيـــة

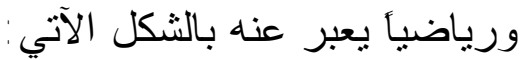
Exne $=\sum_{i=1}^{n} w j$. Ei

$$
\begin{aligned}
& \text { Exne = = سعر الصرف الاسمي الفعلي } \\
& \text { مجموع أوزان التجارة الثنائية للدولة (j) المتاجر معها. }
\end{aligned}
$$

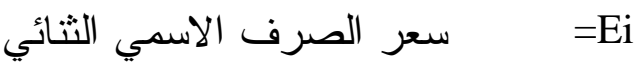

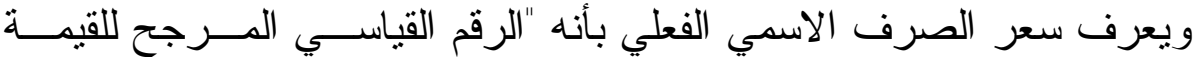

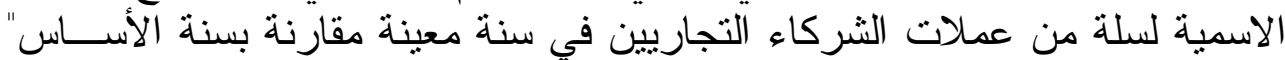

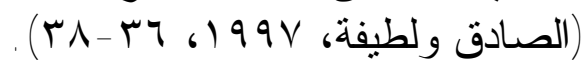

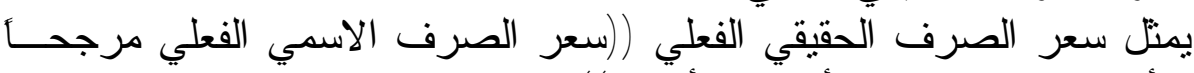

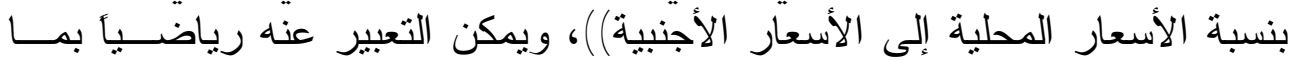

$$
\mathrm{Exre}=\frac{\sum x o^{j}\left(E t^{j i}\right) / x o^{j}\left(E o^{j i}\right)}{\left(P o^{j} / P o^{j}\right) /\left(P t^{j} / p t^{i}\right)}
$$

$$
\text { Exre }=\sum \text { wj IEXR } * 100
$$

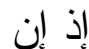
إذ إن IExr يمثل مؤشر سعر الصرف الحقيقي أي: $\mathrm{IExr}=\frac{\text { Exrt }^{i j}}{\text { Exroij }}$

مؤشر سعر الصرف الحقيقي. IExr

Exrt

(o) Exro 


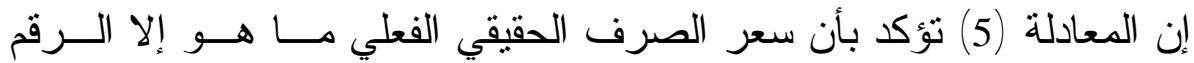

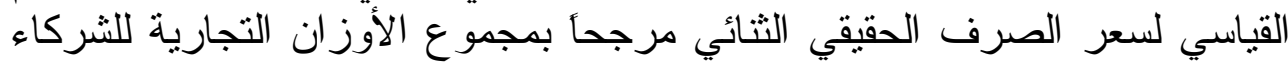
التجاريين ( التيني (

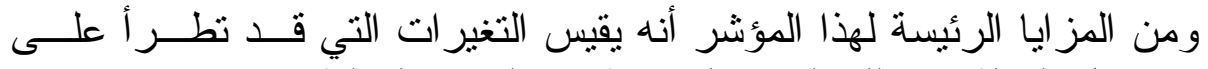

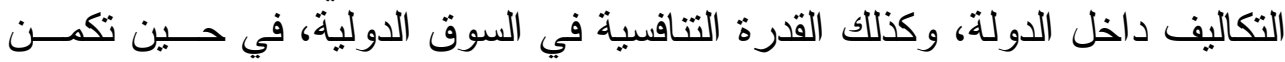

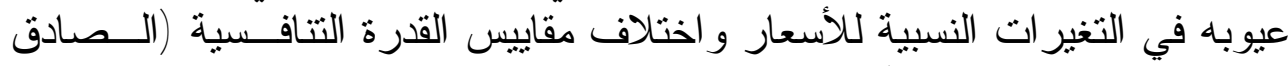

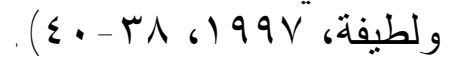

الآلية التأثيرية لتقلبات أسعار الصرف في عدد من متفيرات الاقتصاد الكلي أولاً - التضخم

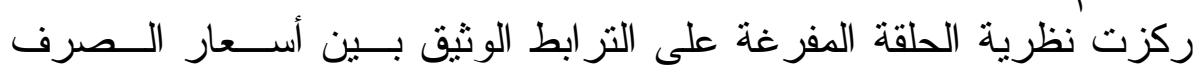

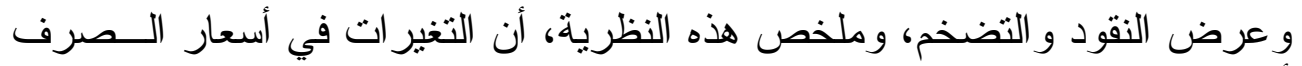

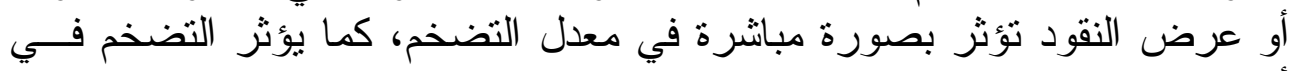

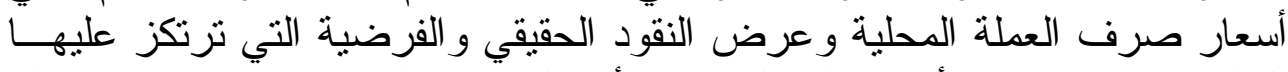

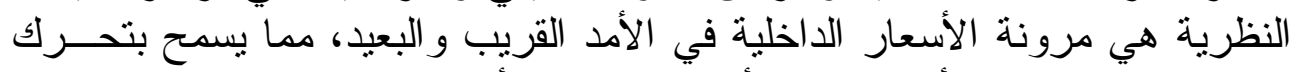

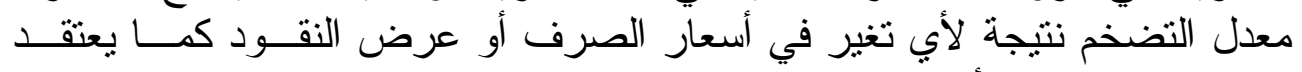

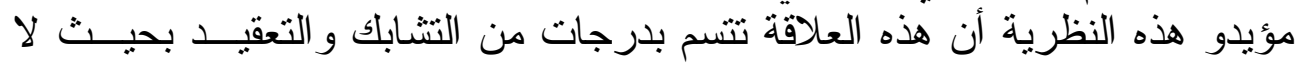

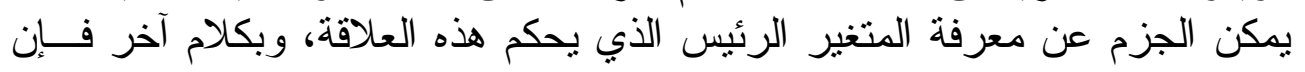

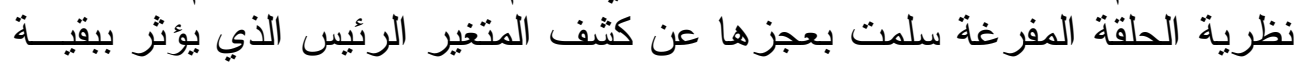

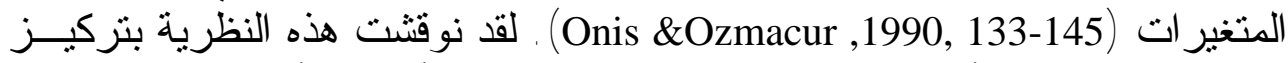

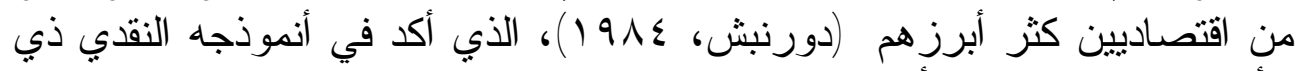

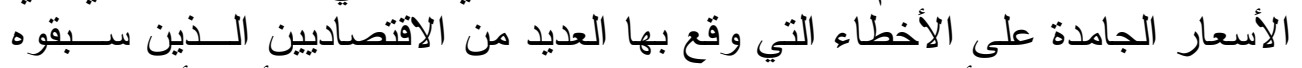

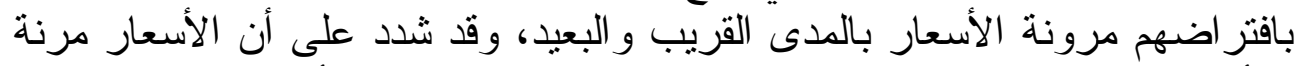

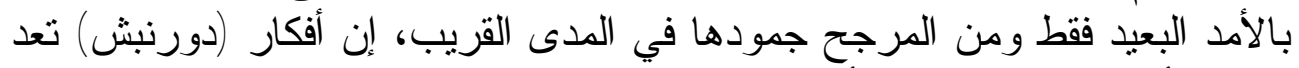

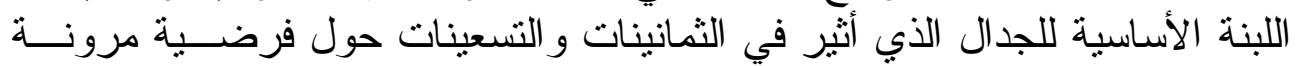

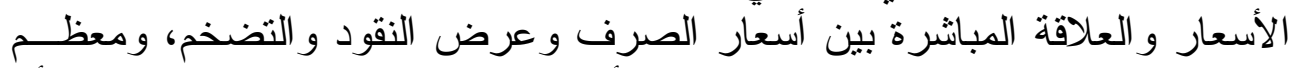

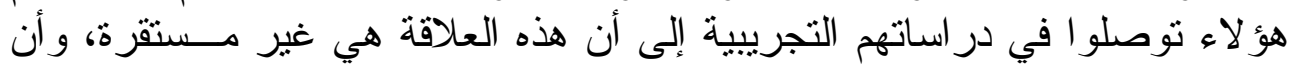

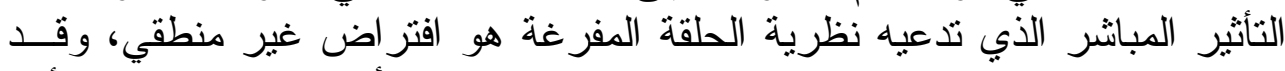

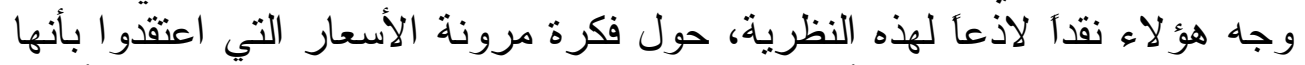

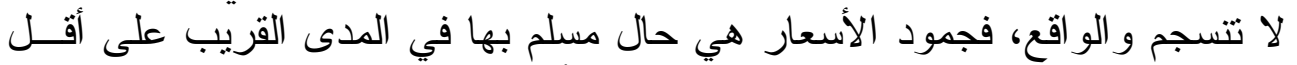

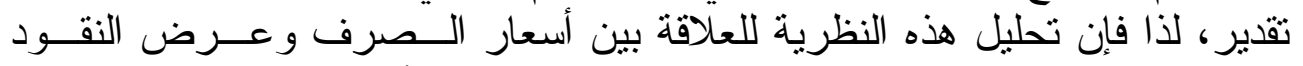

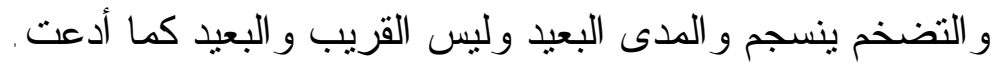

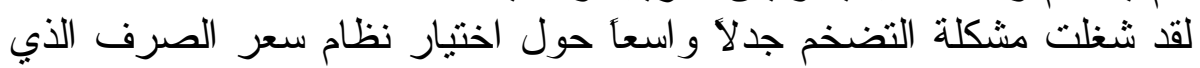

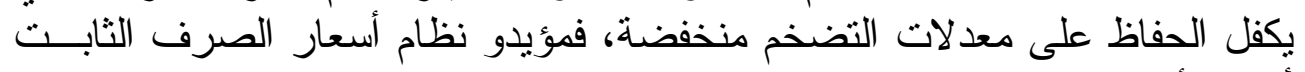

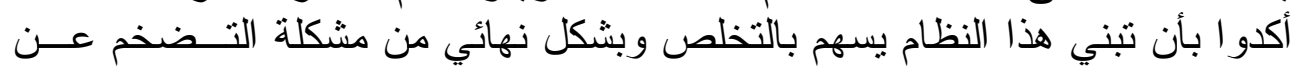


طريق نقييد السياسة النقدية بنظام أسعار الصرف الثنابتة يحتم السيطرة النقدية، و هذا

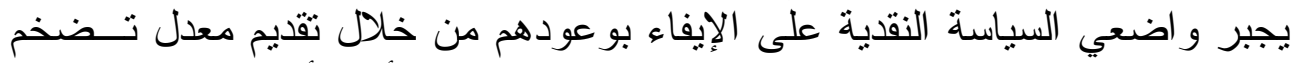

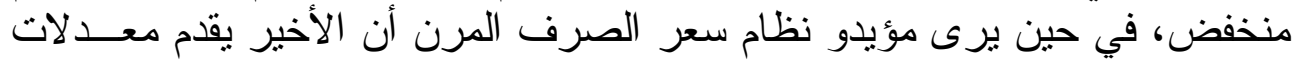

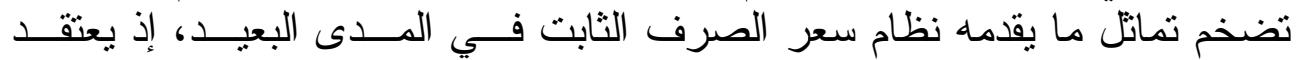

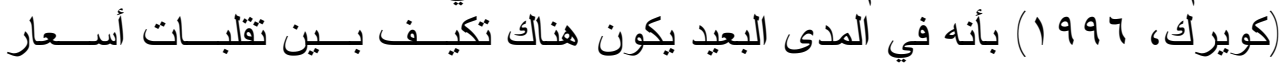

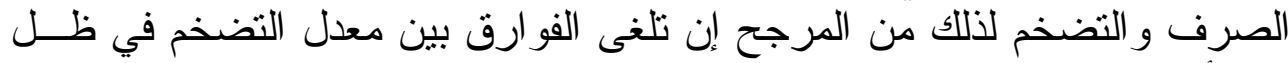

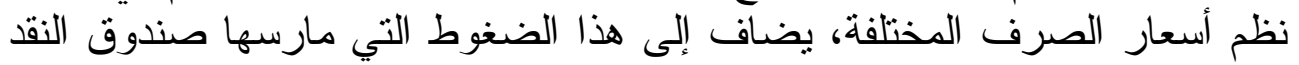

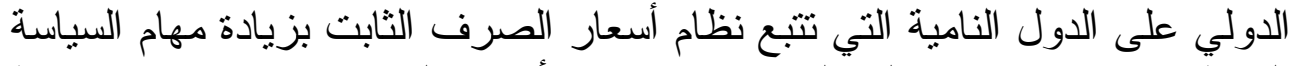

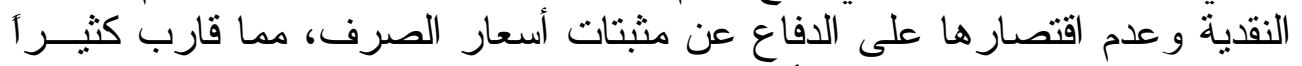

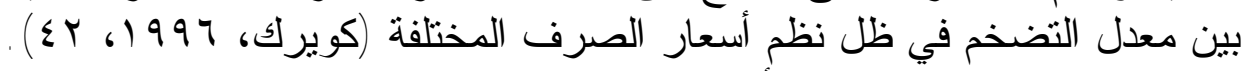

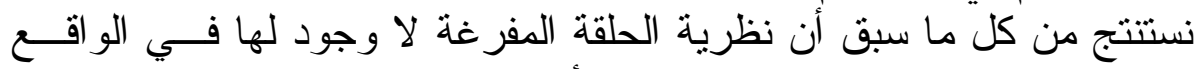

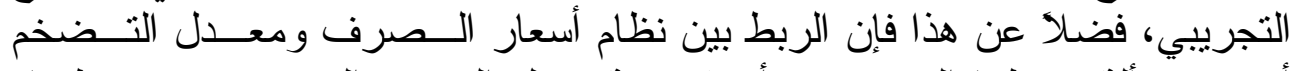

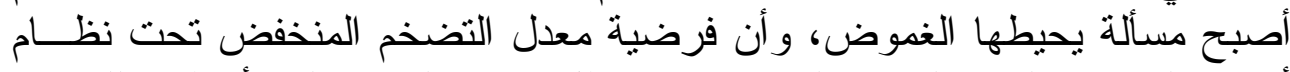

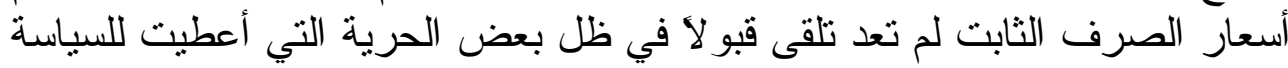
النقدية في هذا النظام.

\section{ثانياً - النمو الاقتصادي}

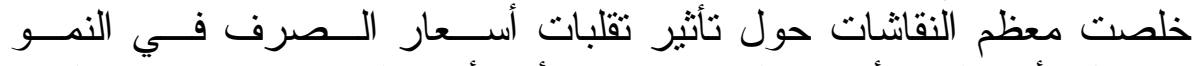

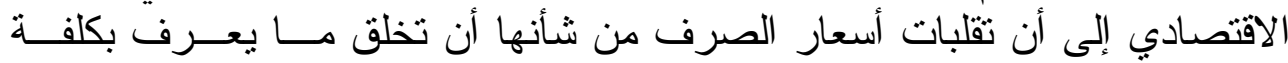

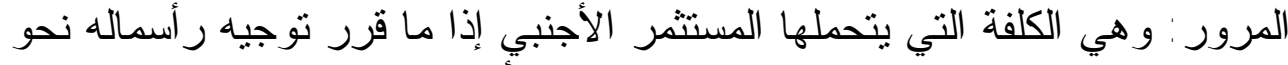

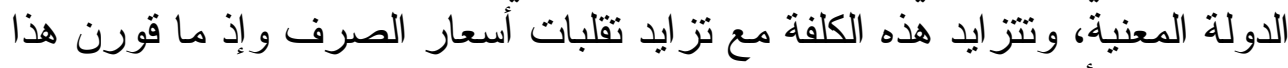

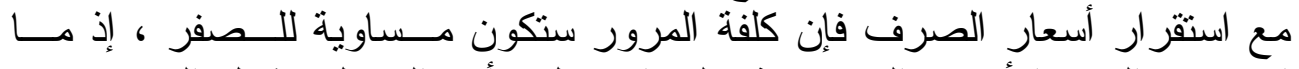

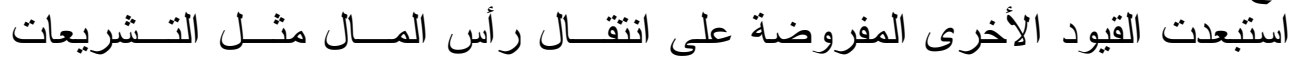

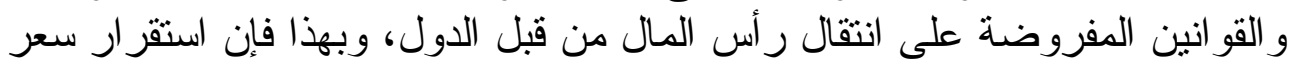

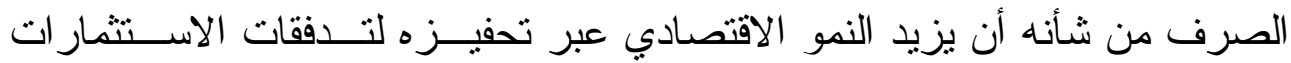

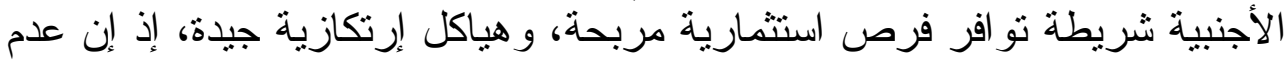

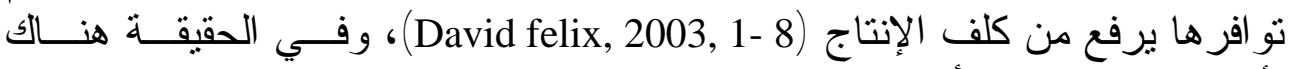

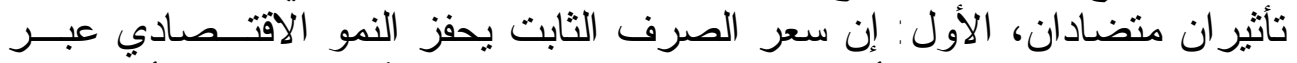

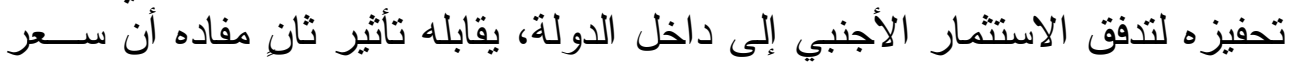

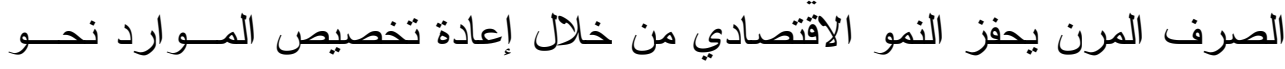

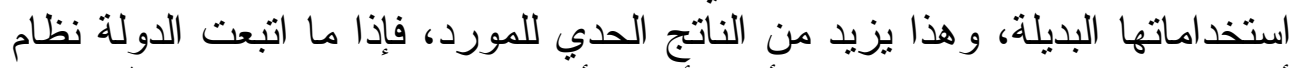

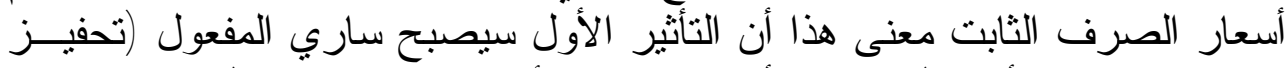

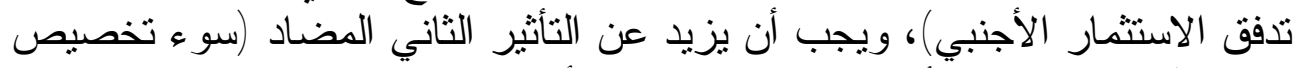

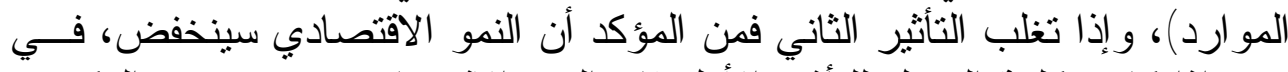

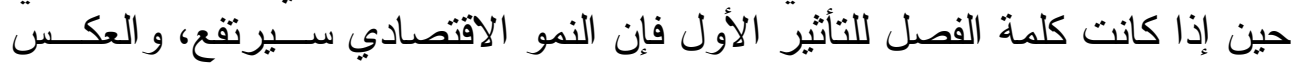

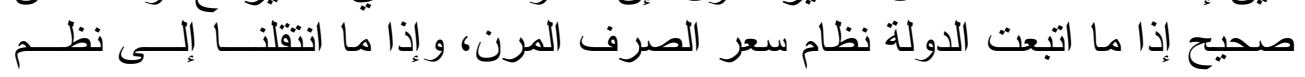




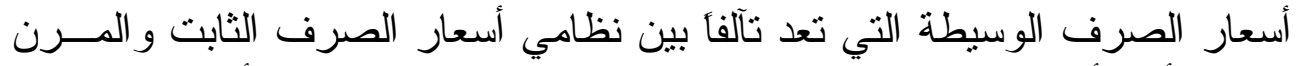

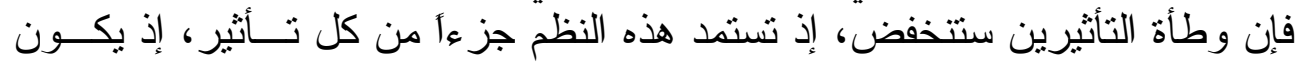

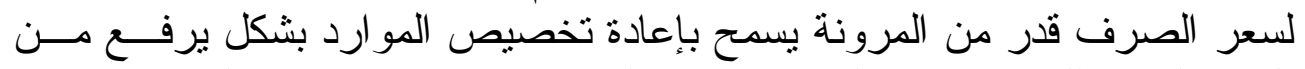

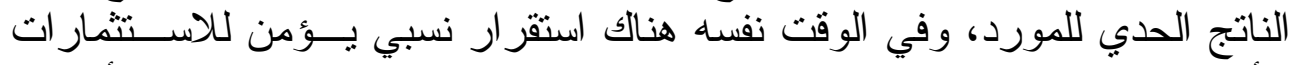

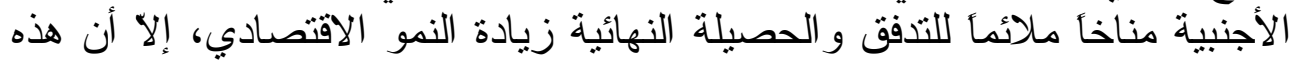

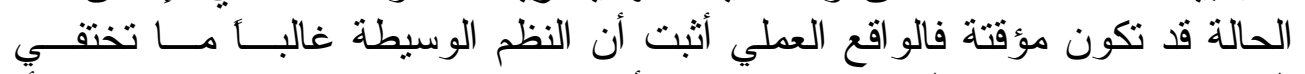

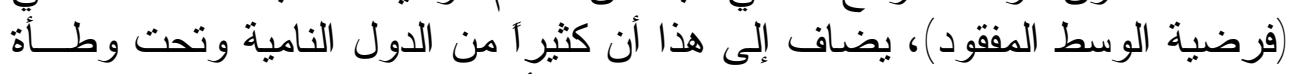

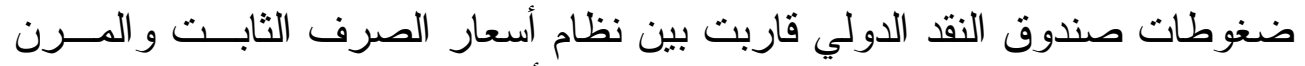

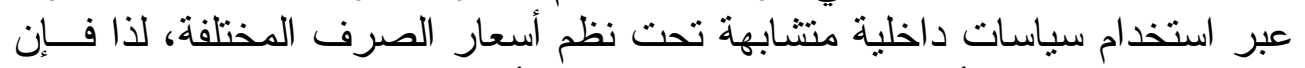

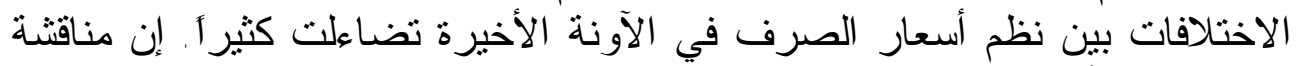

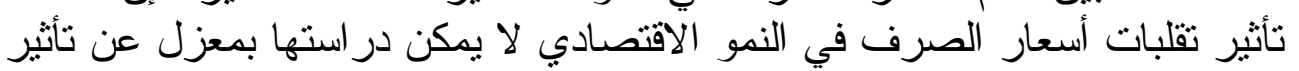

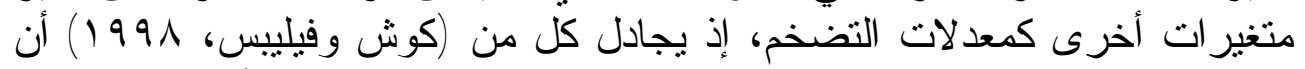

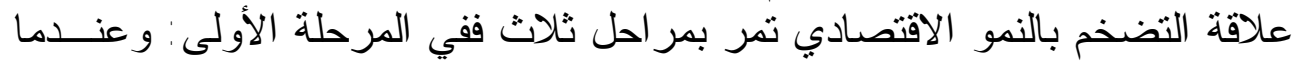

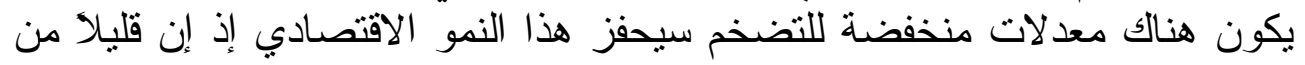

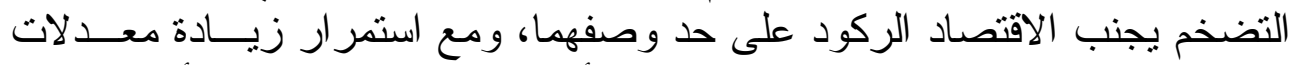

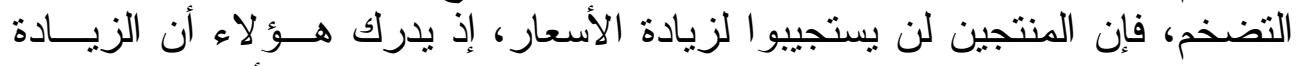

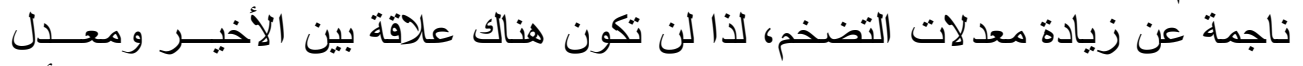

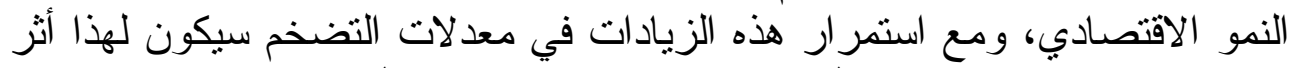
عكسي في النمو الاقتصادي (Harris \& Others, 2004, 2-7).

ثالثاً - تدفقات رأس المال

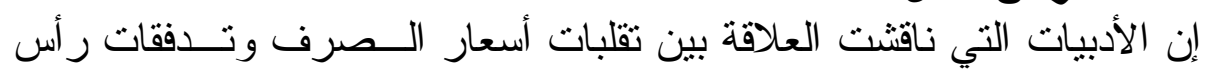

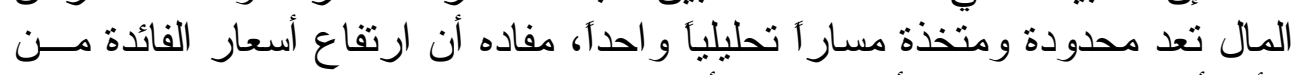

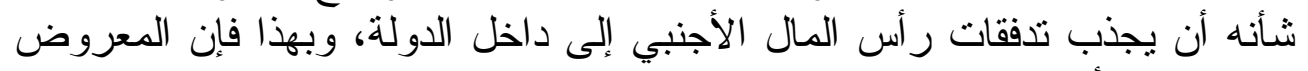

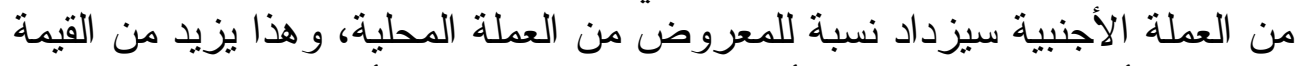

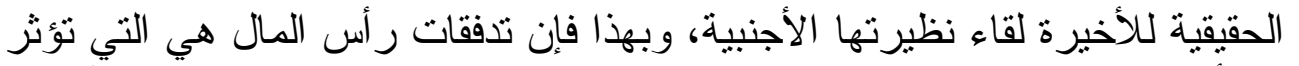

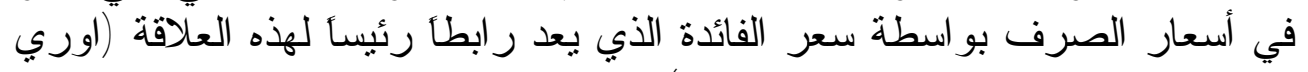

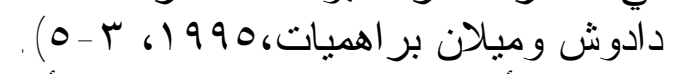

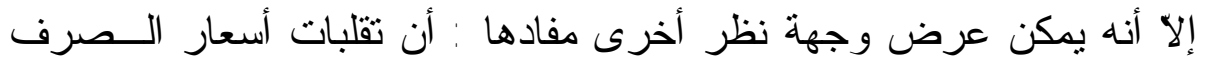

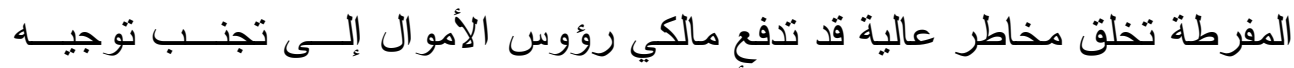

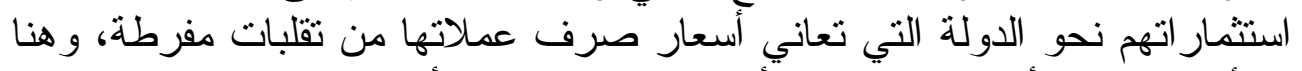

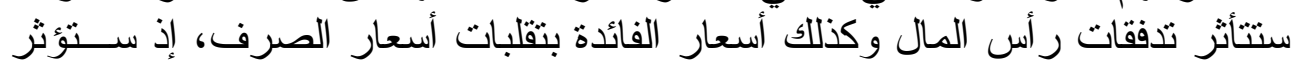

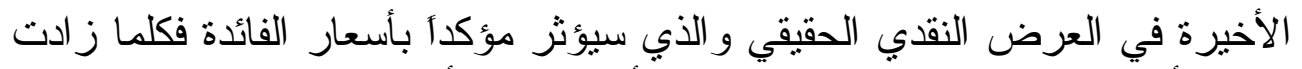

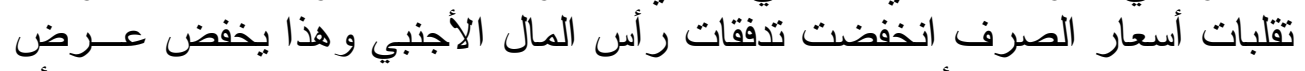

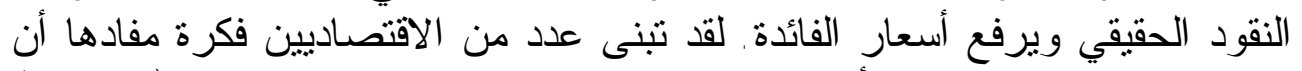

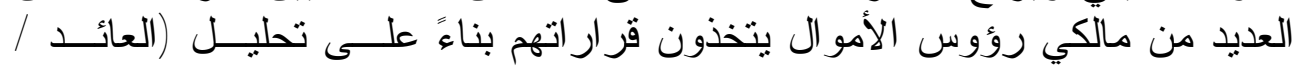


الكلفة)، فإذا اعتقدو أن أرباحهم المتوقعة قد تزيد عن كلف تقلبات أسعار الصرف

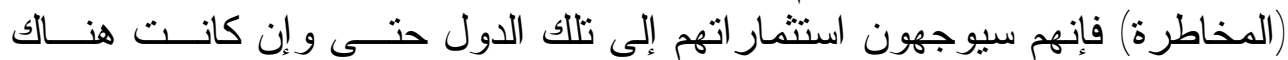

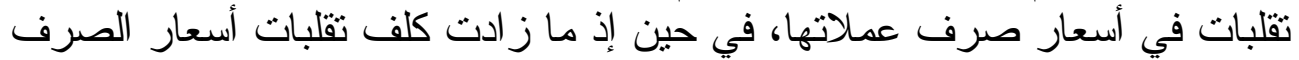

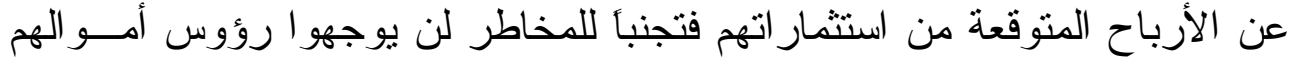
إلى تلك الدول (Glick \& Hutchison ,2002, 1-3) .

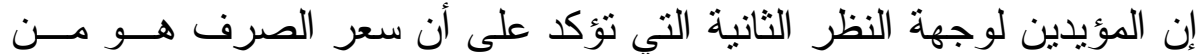

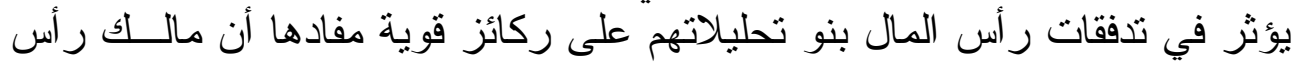

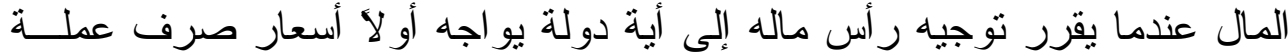

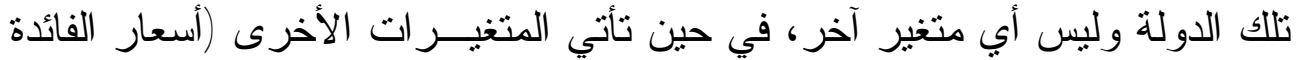
ومعدل التضخم... الخ) تباعاً، ويعتقد مؤيدو هذا الر أي أن استقر ار أسعار الصرف

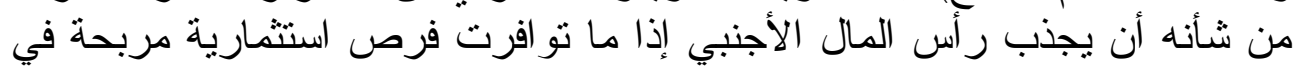

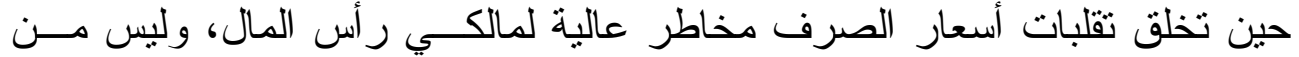

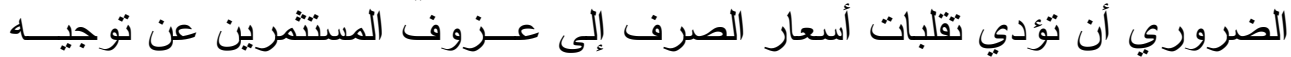

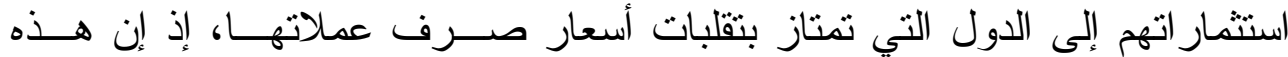

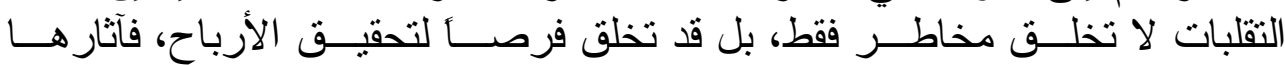

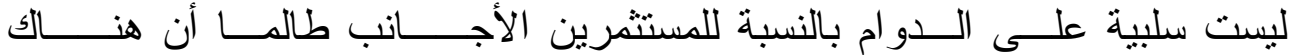

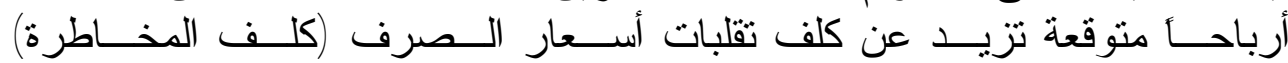
.(Fahrettin Ygci, 2000, 20-21)

التقدير التجريبي لأثر تقلبات سعر الصرف في متغيرات الاقتصاد الكلي الأي

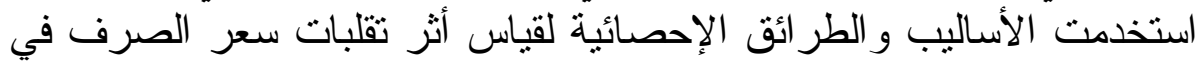

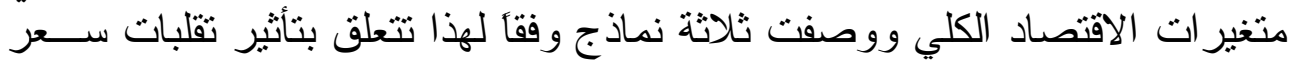

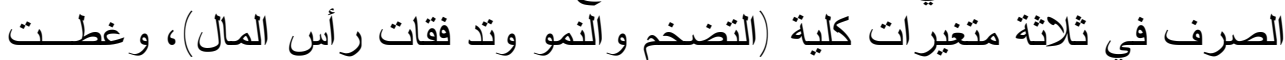

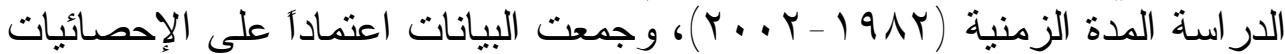
التي ينشر ها صندوق النقد و البنك الدوليين و اختيرت عشر دولئ دول نامية بوصفها عينة

\section{أولاً - توصيف وصياغة النماذج:}

وصفت ثلاثة نماذج لتقدير أثز تقلبات أسعار الصرف فئف في متغير ات الاقتصاد

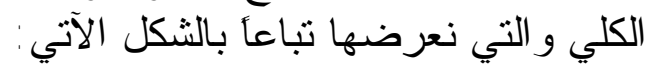

$\mathrm{IN}=\mathrm{b}_{0}+\mathrm{b}_{1} \mathrm{DB}+\mathrm{b}_{2} \mathrm{~S}_{\mathrm{t}}+\mathrm{b}_{3} \mathrm{M}_{\mathrm{t}}+\mathrm{b}_{4} \mathrm{Gp}+\mathrm{b}_{5} \mathrm{In}_{\mathrm{t}-1}+\mathrm{b}_{6} \mathrm{~S}_{\mathrm{t}-1}+\mathrm{b}_{7} \mathrm{M}_{\mathrm{t}-1}+\mathrm{e}_{\mathrm{t}} . .(1)$ $\mathrm{Gr}=\mathrm{b}_{0}+\mathrm{b}_{1} \mathrm{In}_{\mathrm{t}}+\mathrm{b}_{2} \mathrm{~S}_{\mathrm{t}}+\mathrm{b}_{3} \mathrm{M}_{\mathrm{t}}+\mathrm{b}_{4} \mathrm{X} / \mathrm{GDP}+\mathrm{b}_{5} \mathrm{In}_{\mathrm{t}-1}+\mathrm{b}_{6} \mathrm{~S}_{\mathrm{t}-1}+\mathrm{b}_{7} \mathrm{M}_{\mathrm{t}-1}+\mathrm{e}_{\mathrm{t}}$. (2) $\mathrm{CA}=\mathrm{a}_{0}+\mathrm{b}_{1} \mathrm{In}_{\mathrm{t}}+\mathrm{b}_{2} \mathrm{St}+\mathrm{b}_{3} \mathrm{I} / \mathrm{GDp}+\mathrm{b}_{4} \mathrm{In}_{\mathrm{t}-1}+\mathrm{b}_{5} \mathrm{~S}_{\mathrm{t}-1}+\mathrm{e}_{\mathrm{t}}$ 


$$
\text { المعادلة (1) تبين متغير التضخم وفيها: }
$$

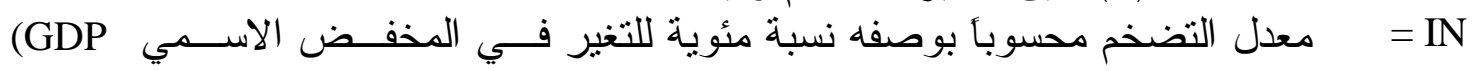
defeltor)

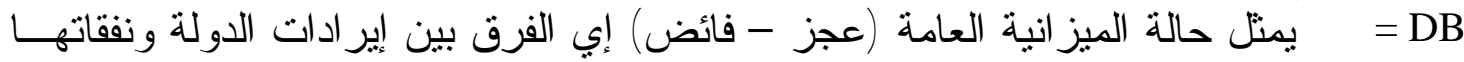

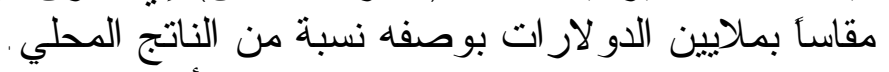

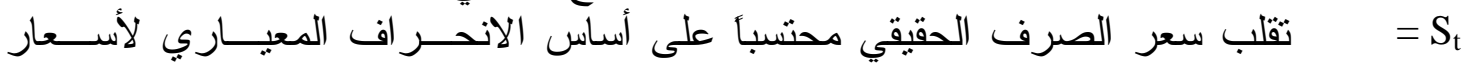

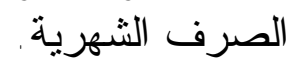
= M النمو السنوي للمعروض النقدي بوصفه نسبة مئوية. = = Gp

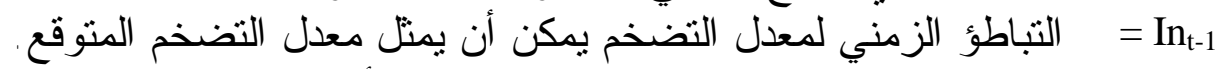

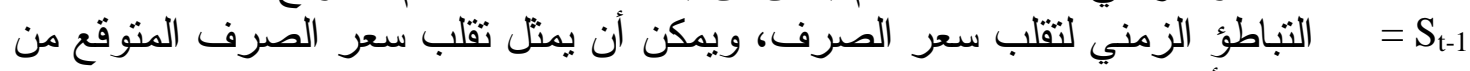

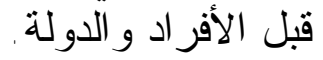

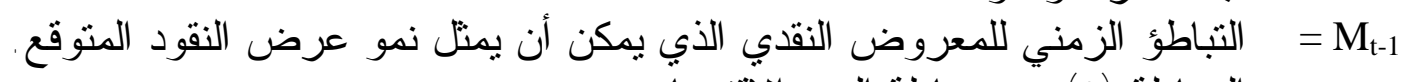

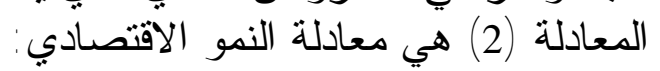
= Gr كما موضح سابقاً.

X/GDP

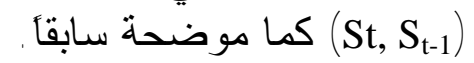
المعادلة (4) تمنل معادلة التدفق الر أسمالي الخاص:

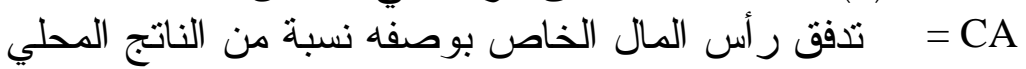
كما موضح سابقا (St-1 I أجمالي الاستثمار بوصفه نسبة من الناتج المحلي (GDP) =I/ ( $=\left(b_{0}, b_{1}-b_{7}\right)$

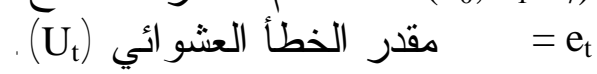
وستقدر النماذج الثلاثة بإتباع طريقة المربعات الصغرى الاعتيادية (OLS) .

ثانياً - تفسير النتائج التقديرية لأثر تقلبات سعر الصرف في متغيرات الاقتـصاد

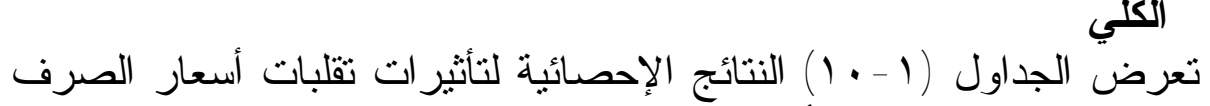

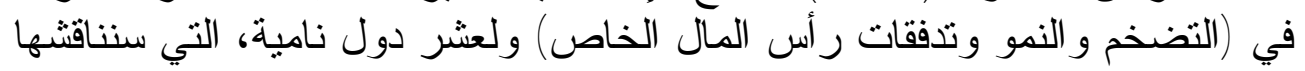
مبتّئين بمعادلة التضخم. 


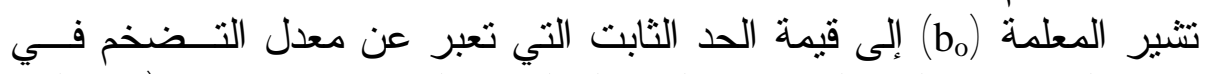

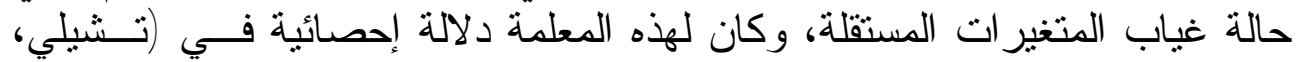

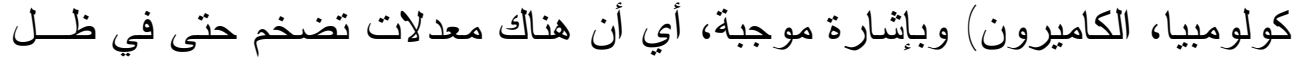

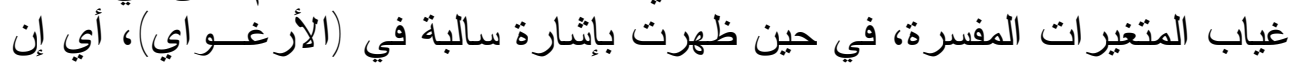

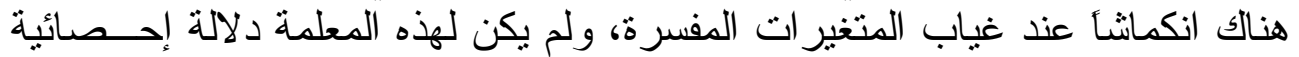

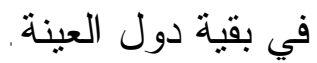
وتمثل (b $b_{1}$ معلمة قيد الميز انية، ولم تظهر هذه المعلمة بمستوى المعنوية في

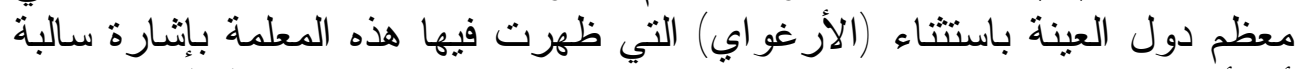

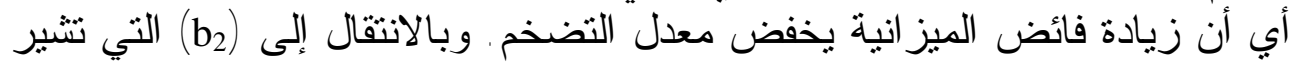

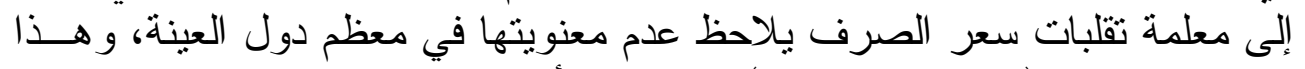

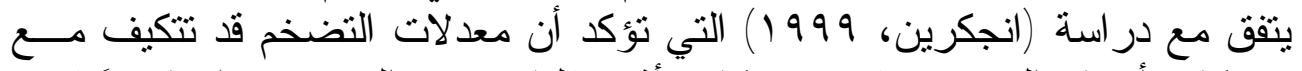

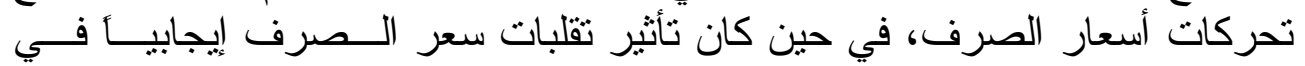

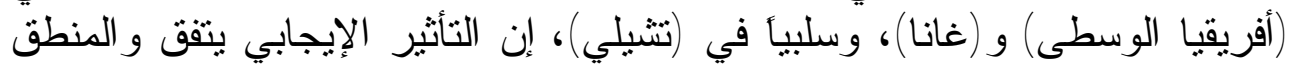

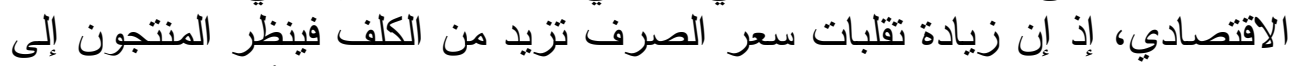

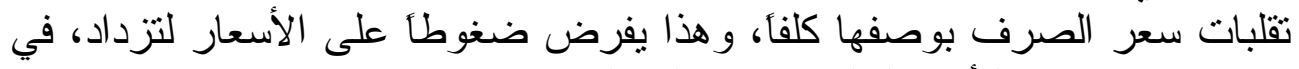

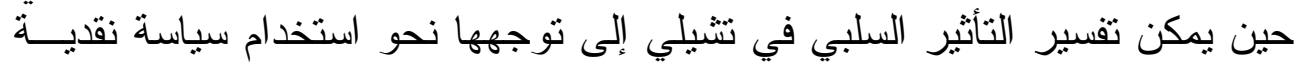

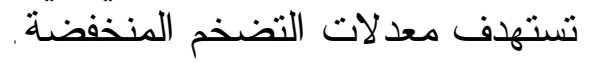

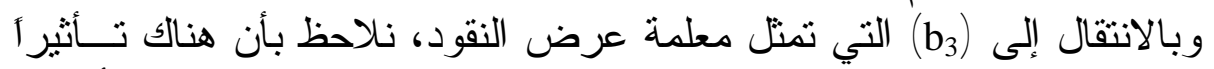

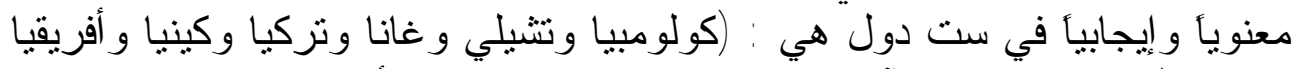

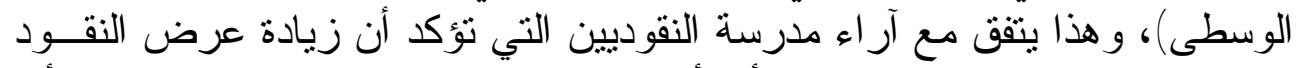

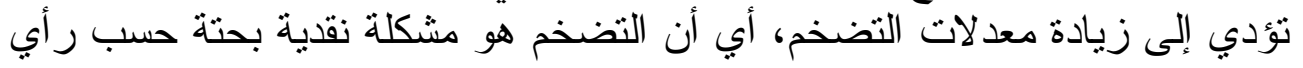

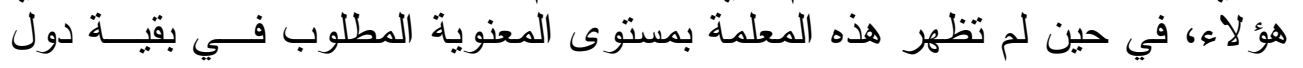
العينة.

و تتشير (b4) إلى معلمة نمو الناتج المحلي بالأسعار الجارية، وكان تأثير هذا

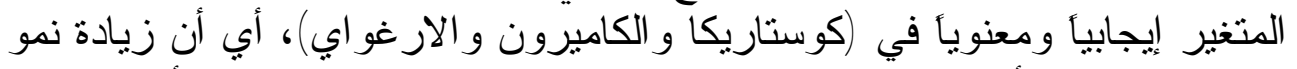

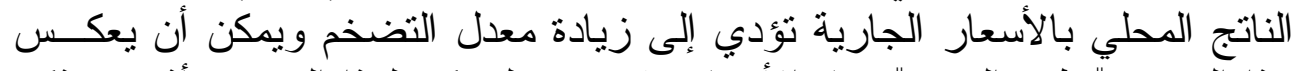

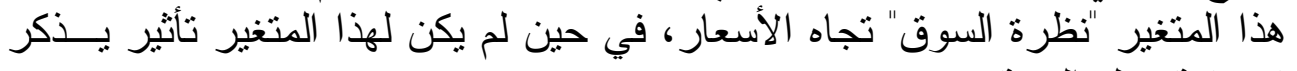
في بقية دول العينة . وتبين (b5) معلمة التباطؤ الزمني لمعدل التضخم الذي الذي يمكن أن بعكس معدل

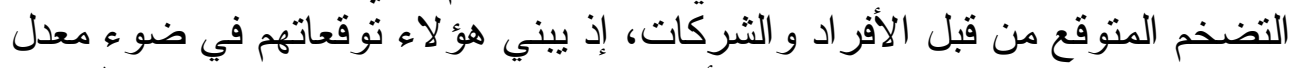

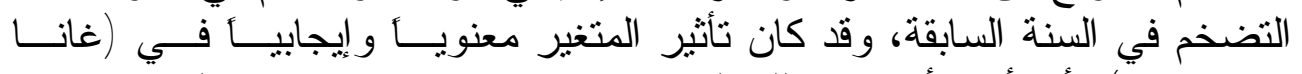

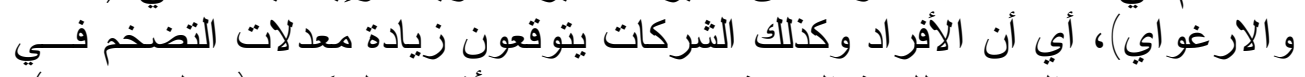

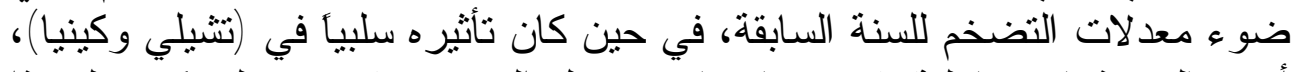

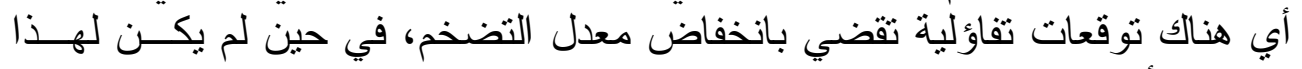
المتغير تأثير يذكر في بقية دول فئ العينة. 


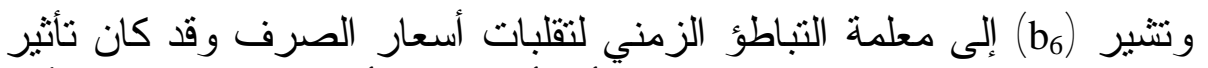

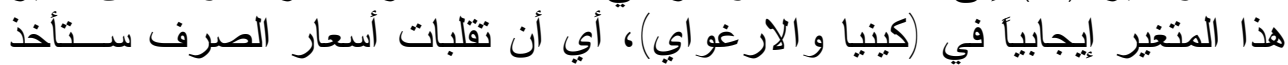

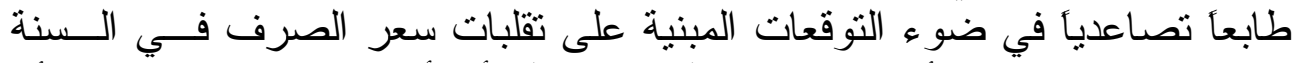

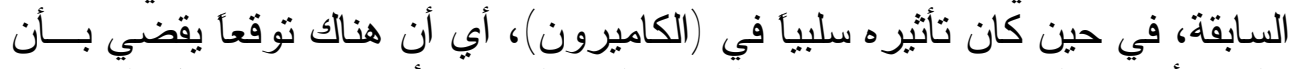

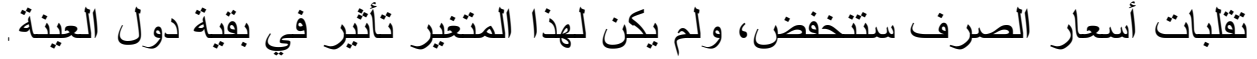

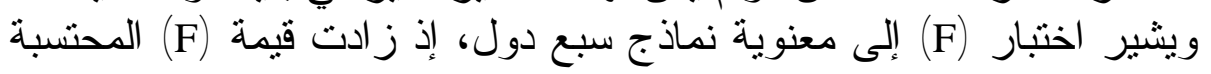

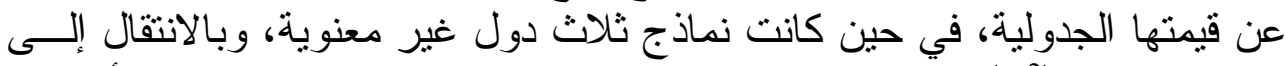

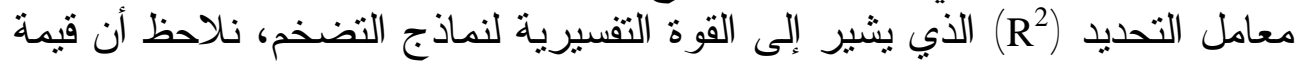

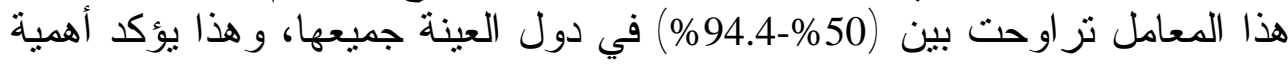

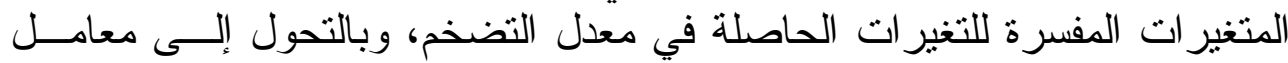

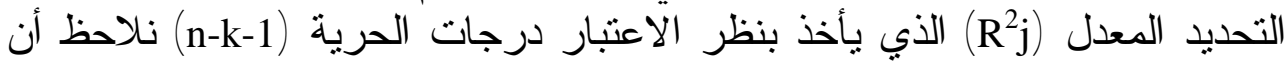

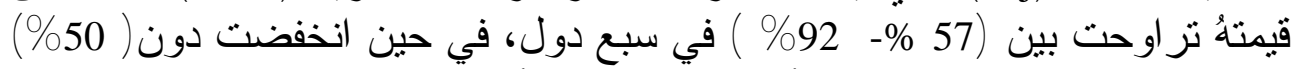

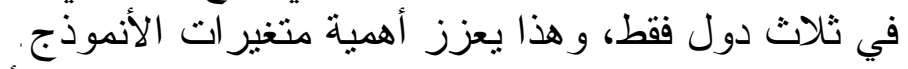

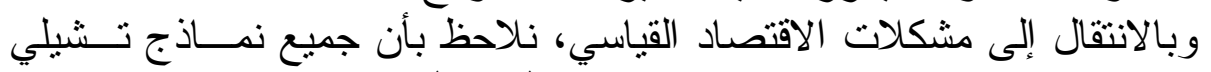

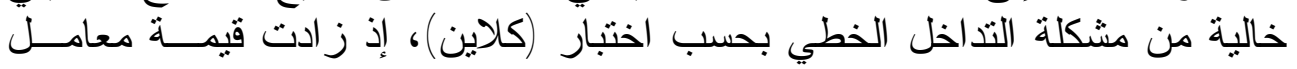

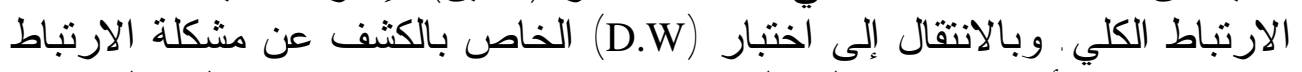

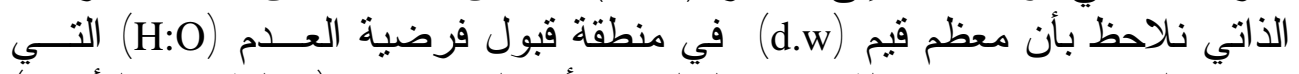

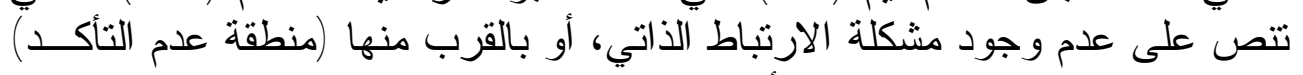

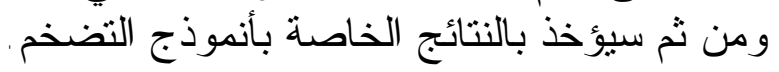

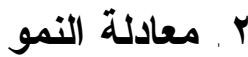

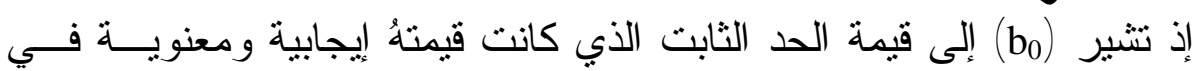

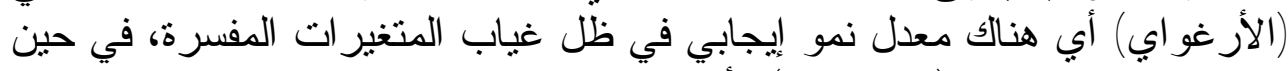

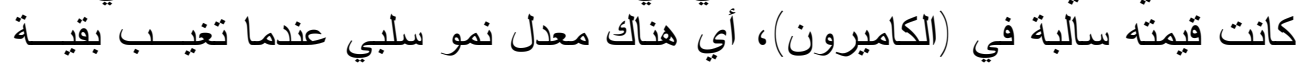

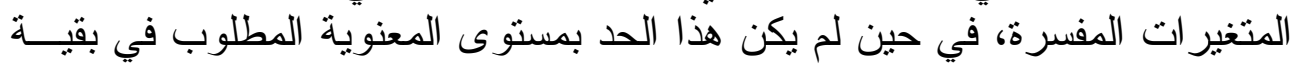

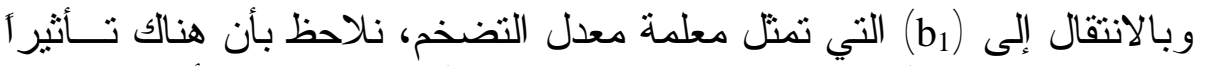

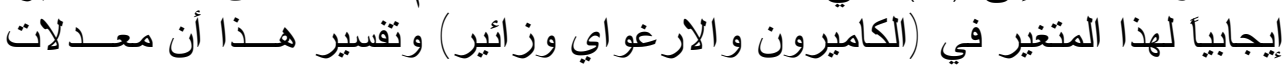

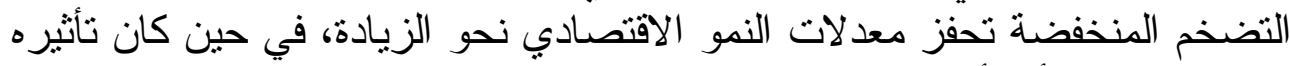

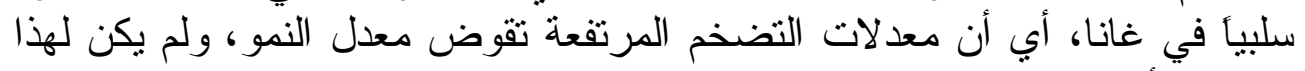

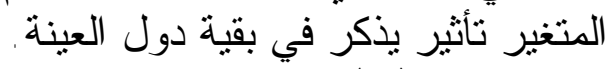

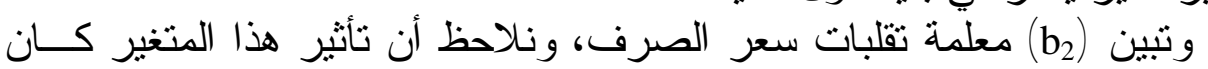

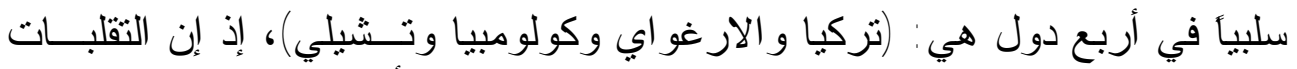

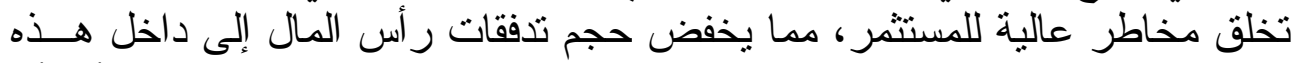

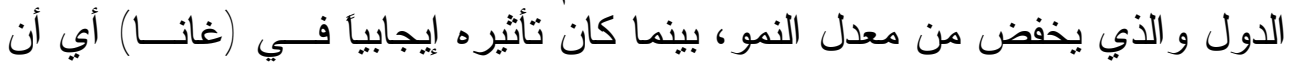




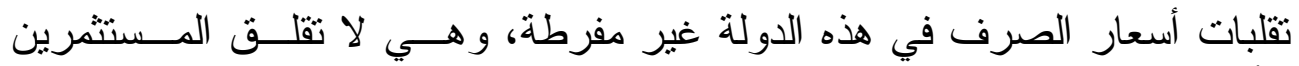

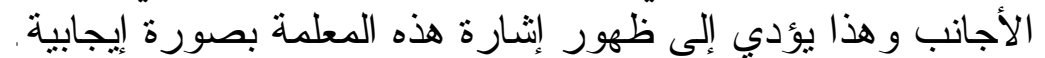

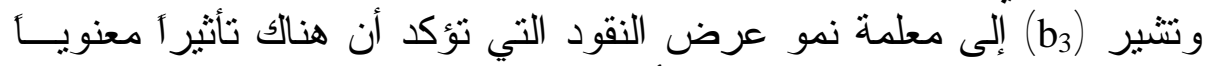

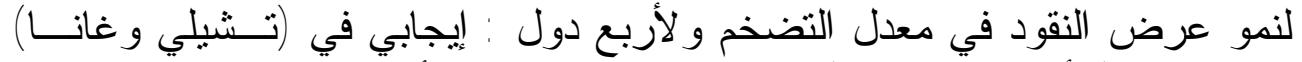

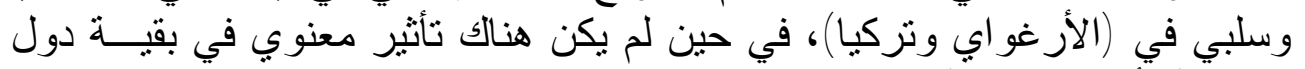
العينة (التأثير الحيادي) (الإي)

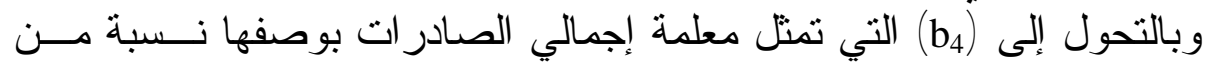

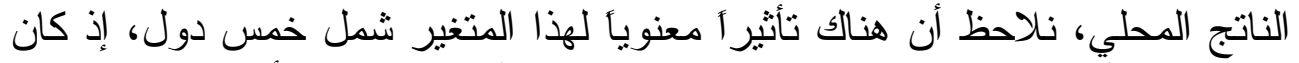

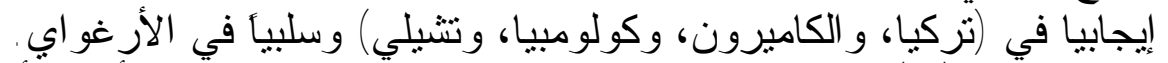

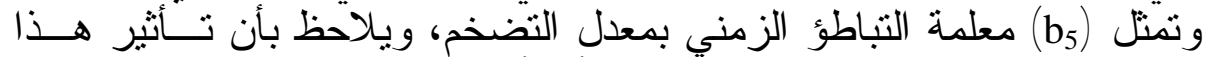

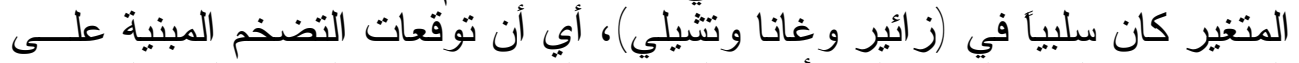

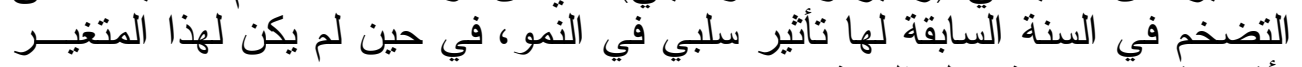
تأثير بذكر في بقية دول التينة العينة.

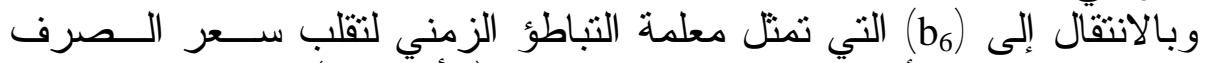

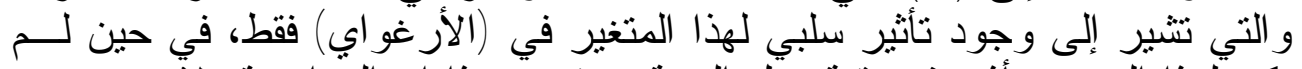

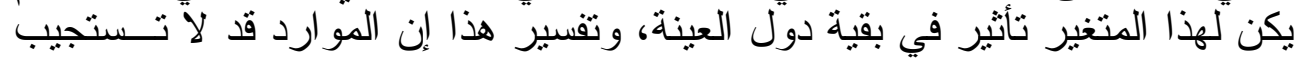

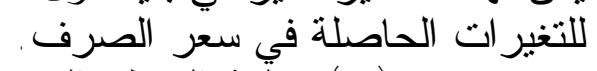

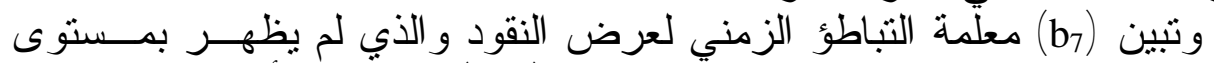

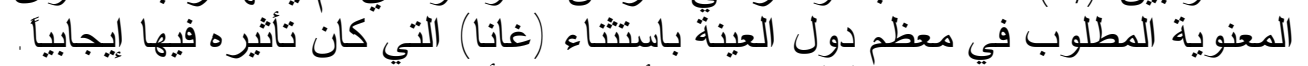

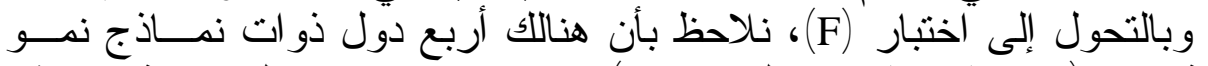

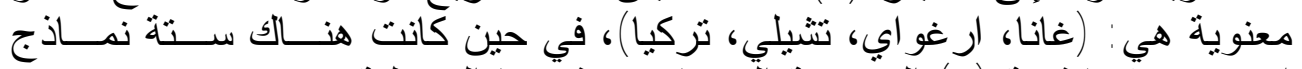

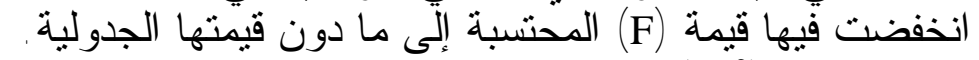

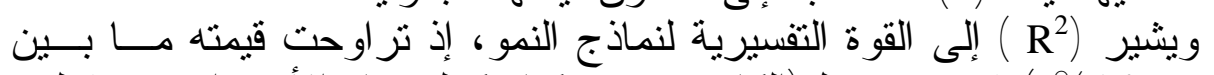

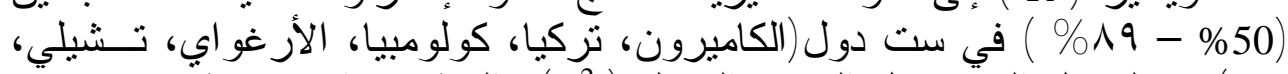

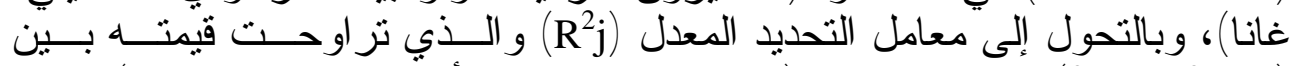

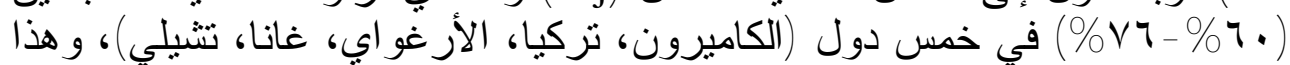

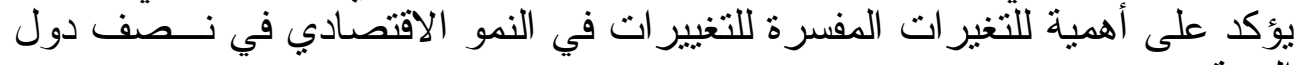

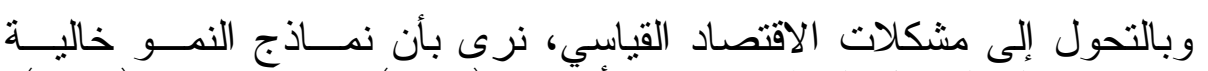
العينة.

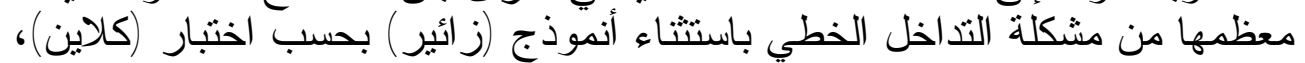

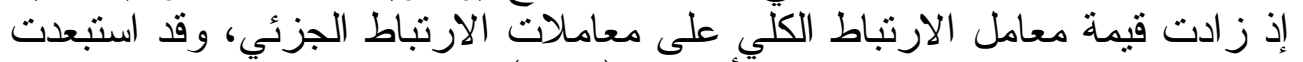

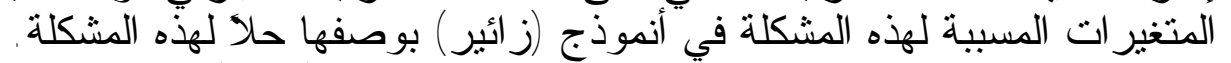

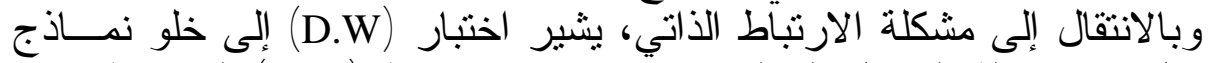

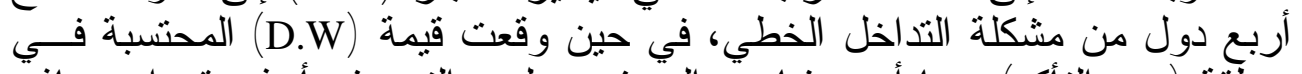

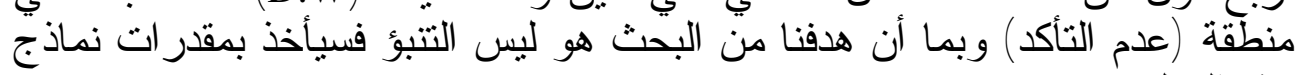

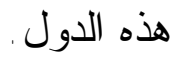




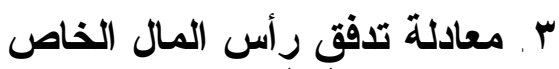

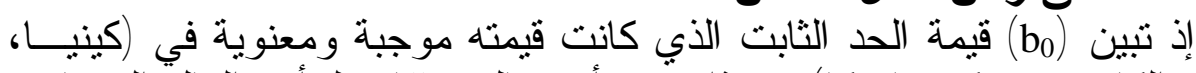

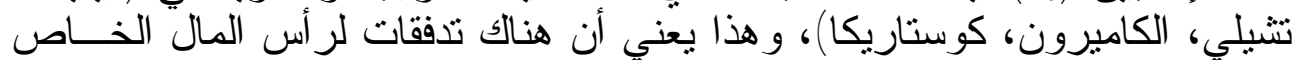

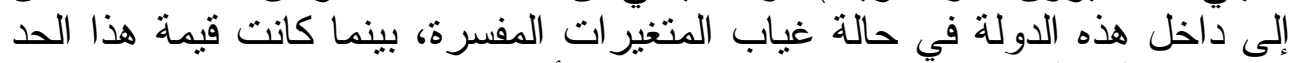

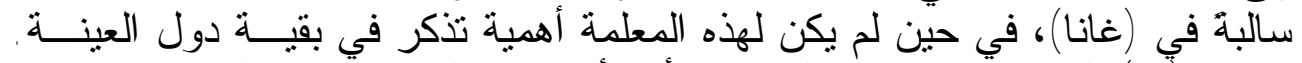

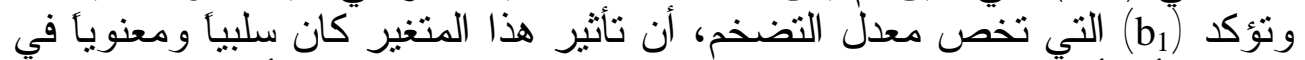

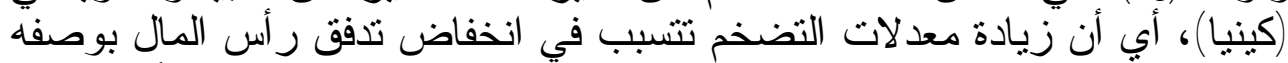

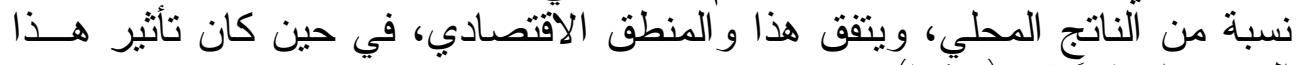

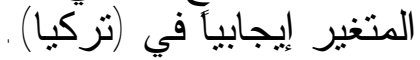

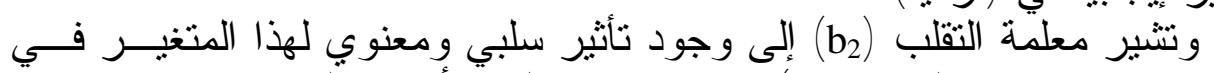

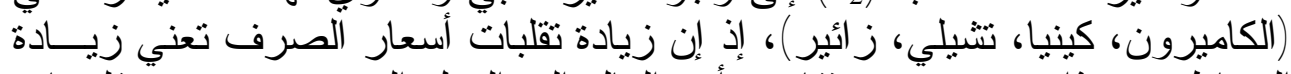

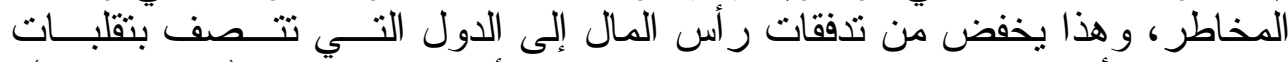

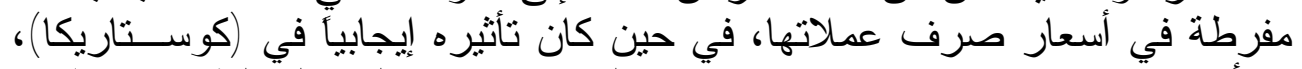

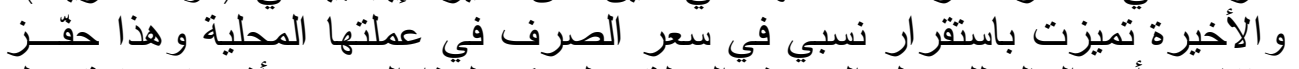
تدفقات ر أس المال للاخول إلى هذه الدولة، ولم يكن لهذار المتغير تأثير في بقية دولئ

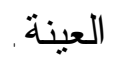

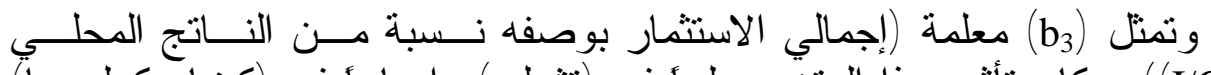

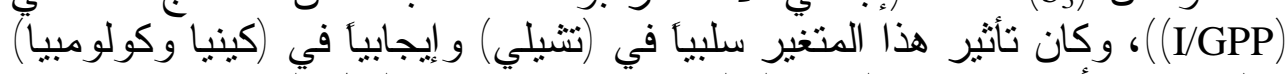

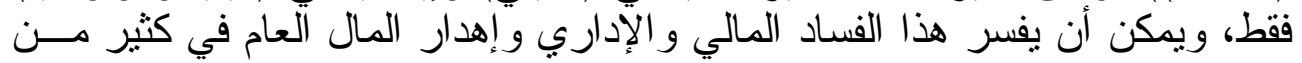

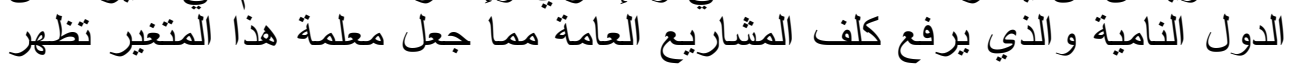

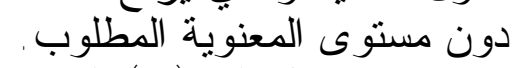

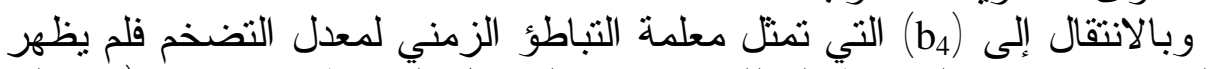

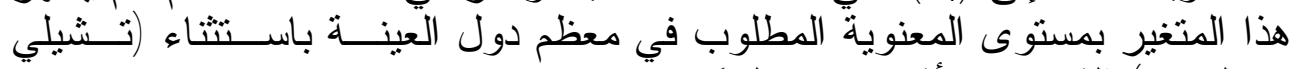
وكولومبيا) الذي كان تأثيره فيها سلبياً.

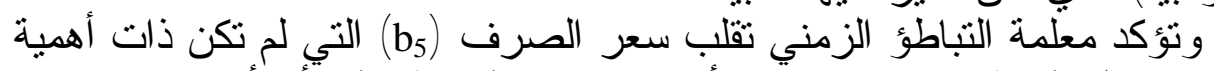

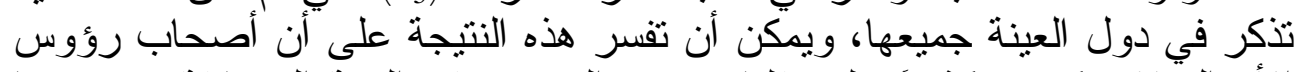

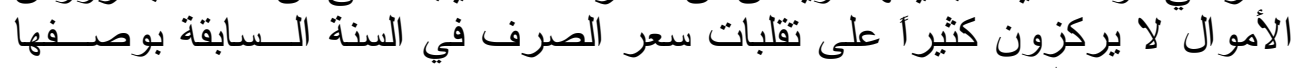

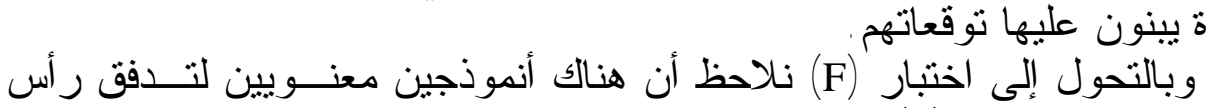

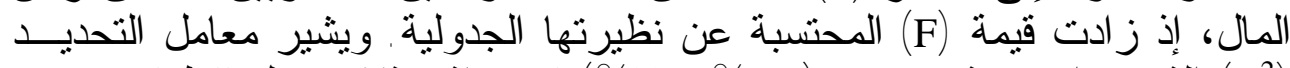

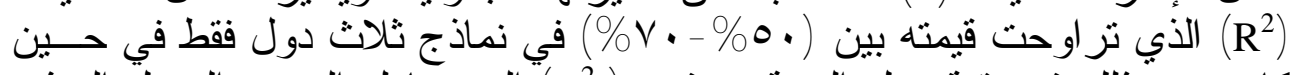

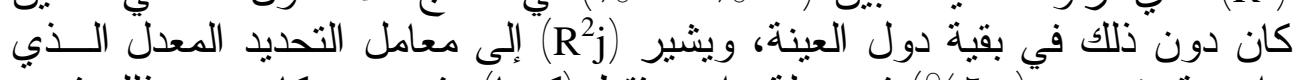

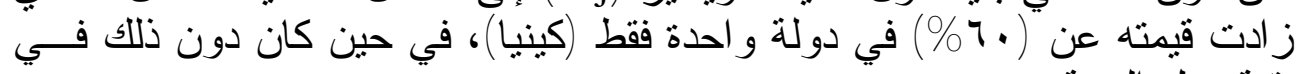

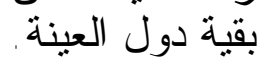
وبالتحول إلى الاختبار ات المتعلقة بالكثف عن وجود المشاكل الإحـصـائية،

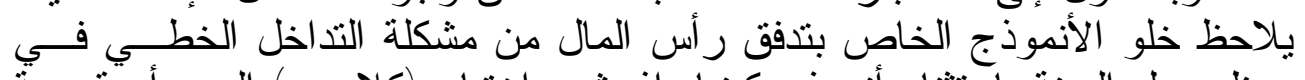

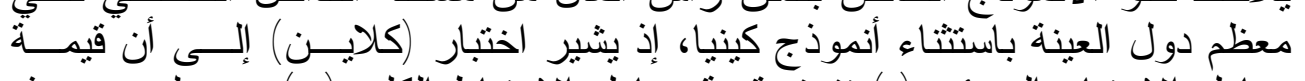

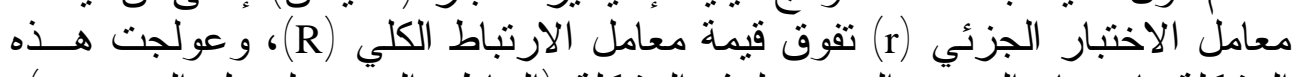

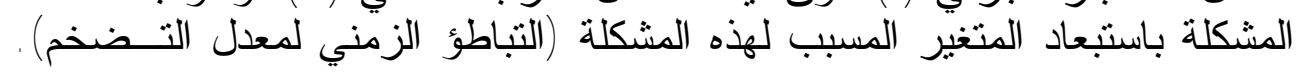


كما يشير اختبار (D.W) الخاص بالكثف عن مشكلة الارنباط الذاتي خلو نمــاذج

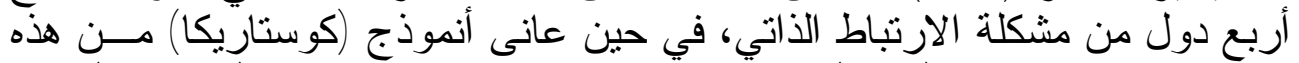

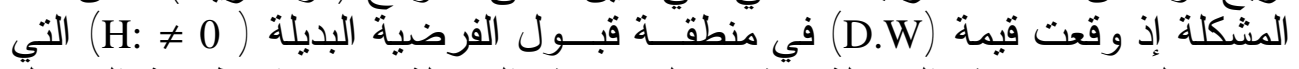

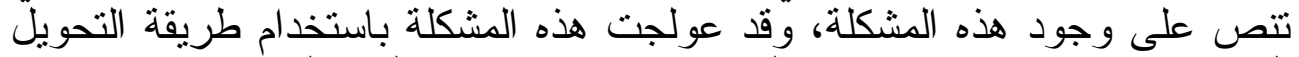

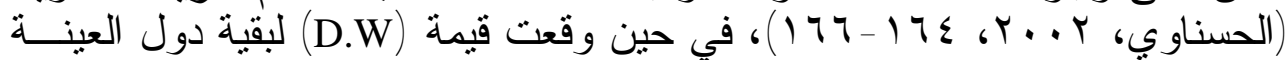

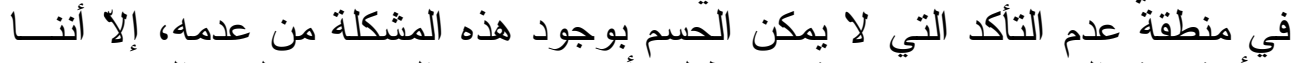

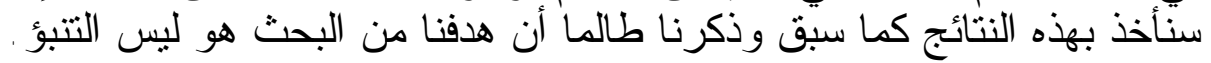

\section{التائج و المقترحات \\ أولاً - النتائج و المئج}

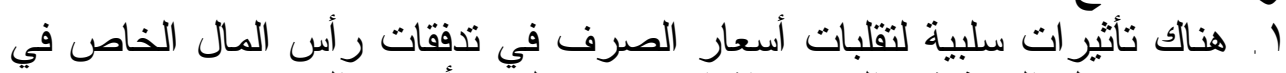

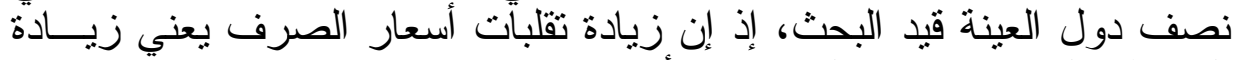

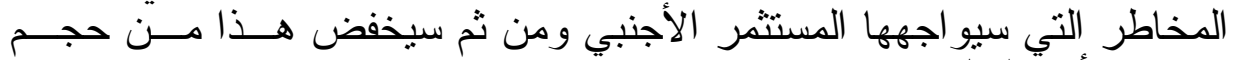
تدفقات ر أس المال .

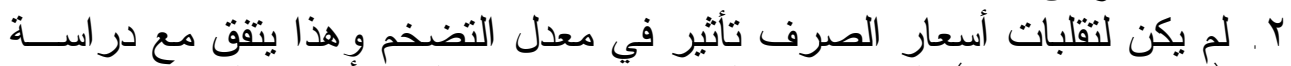

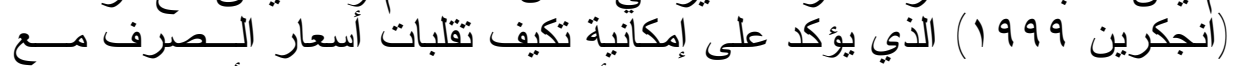

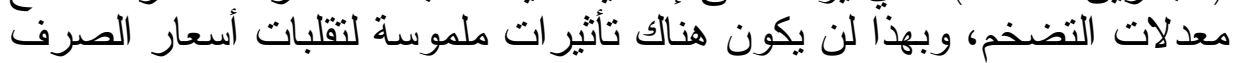

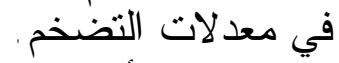

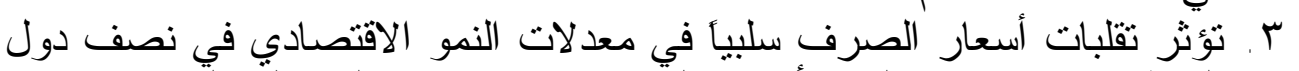

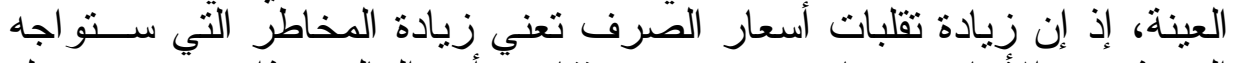

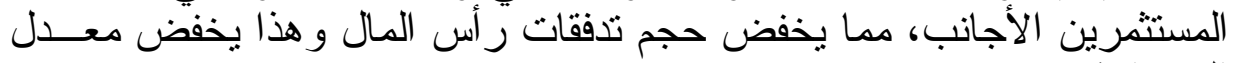

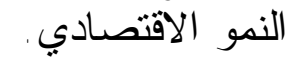
ـ . عززت النتائج الإحصائية أفكار المدرسة النقدية، التي تؤكد أن مشكلة التضخم

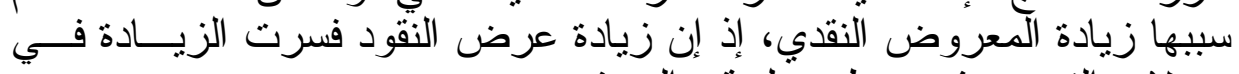

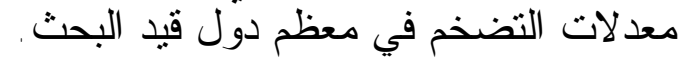

$$
\text { ثانياً - المقترحات }
$$

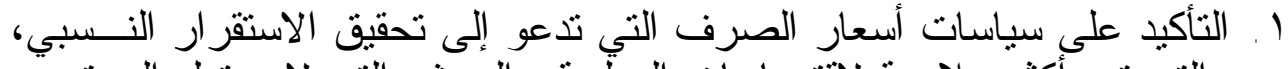

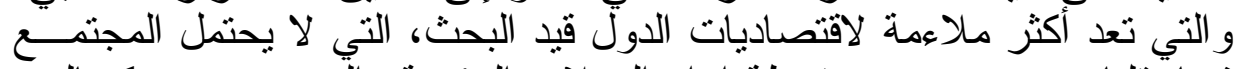

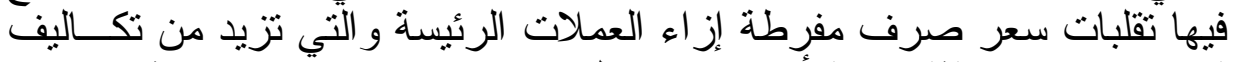

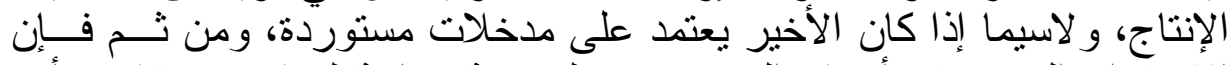

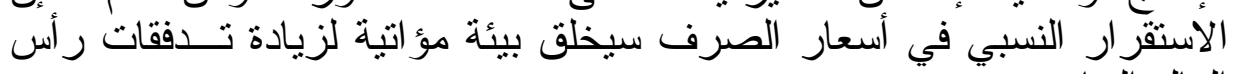
المال الخاص. - الاص.

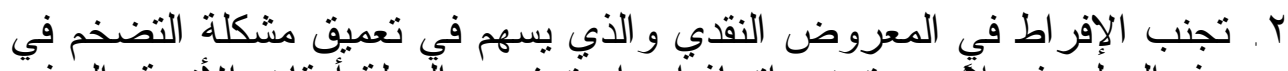

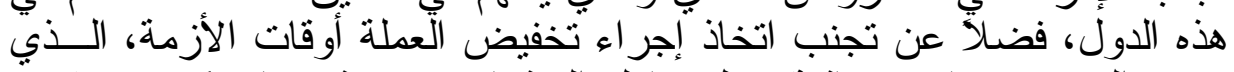

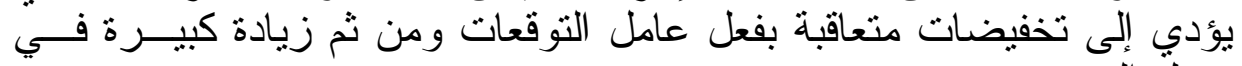

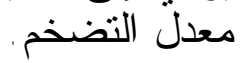




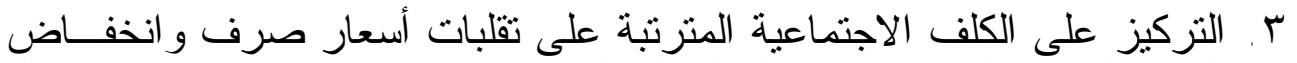

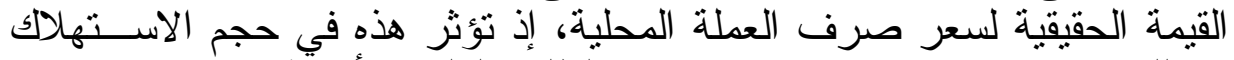

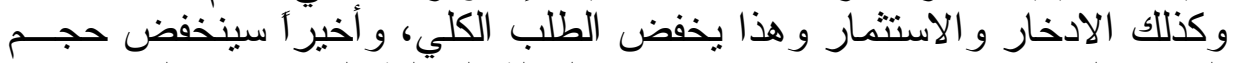
العو ائد المتوقع من تخفيض سعر صرف الإف العملة المحلية التي تهدف إلى زيــادة القدرة التنافسية للصنادر ات في السوق الخارجية.

\begin{tabular}{|c|c|c|c|c|c|c|c|c|c|c|c|c|}
\hline \multicolumn{13}{|c|}{ الثنتلن الاحصدبة المخاصة } \\
\hline & $b_{4}$ & $\mathrm{~B}_{1}$ & $b_{2}$ & $b_{3}$ & $\mathrm{~b}_{4}$ & h, & $b_{6}$ & $b_{7}$ & $\mathbf{F}$ & $\mathbf{R}^{1}$ & $\mathbf{R}^{2} \mathbf{j}$ & D.W \\
\hline معلئة التضخ & $\begin{array}{l}-3.34 \\
0.666 \\
\end{array}$ & $\begin{array}{l}.0 .042 \\
-1.06 \\
\end{array}$ & \begin{tabular}{|l|}
0.24 \\
0.75 \\
\end{tabular} & $\begin{array}{l}0.25 \\
1.5 \\
\end{array}$ & \begin{tabular}{|l|}
0.393 \\
0.86 \\
\end{tabular} & $\begin{array}{l}-0.107 \\
0.7\end{array}$ & $\begin{array}{l}0.82 \\
0.5 \\
\end{array}$ & $\begin{array}{l}0.905 \\
5.9 \\
\end{array}$ & 63 & 78.5 & 66 & 1.78 \\
\hline معادلة النصو الغطصادي & $\begin{array}{l}4.21 \\
0.75 \\
\end{array}$ & $\begin{array}{l}0.147 \\
2.17 \\
\end{array}$ & $\begin{array}{l}0.082 \\
0.71 \\
\end{array}$ & $\begin{array}{c}0.043 \\
-0.98 \\
\end{array}$ & $\begin{array}{l}-0.102 \\
-1.50 \\
\end{array}$ & $\begin{array}{l}-0.15 \\
1.77 \\
\end{array}$ & 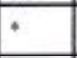 & . & 1.7 & 43.6 & 33,7 & 2.17 \\
\hline بعلة حسف رذي فل & \begin{tabular}{|l|}
10.3 \\
0.89 \\
\end{tabular} & $\begin{array}{l}-0.047 \\
-0.33\end{array}$ & \begin{tabular}{|l|}
0.465 \\
-1.77 \\
\end{tabular} & $\begin{array}{l}0.36 \\
0.8 \\
\end{array}$ & $\begin{array}{l}0.045 \\
0.75 \\
\end{array}$ & $\begin{array}{l}0.204 \\
0.66 \\
\end{array}$ & & & 0.79 & 19 & 7.5 & 1.97 \\
\hline \multicolumn{13}{|c|}{ 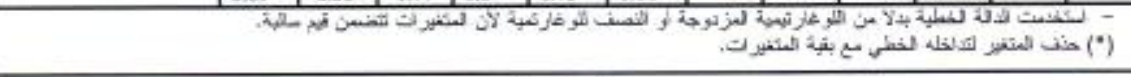 } \\
\hline \multicolumn{13}{|c|}{ 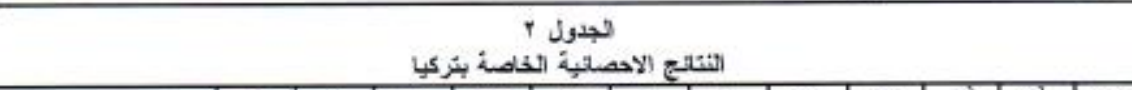 } \\
\hline & $b_{g}$ & $b_{1}$ & $b_{2}$ & $b_{3}$ & $b_{4}$ & $\mathrm{~b}_{5}$ & $b_{c}$ & b, & $\mathbf{F}$ & $\mathbf{R}^{2}$ & $\mathbf{R}^{2} \mathbf{j}$ & D.w \\
\hline معلة المضخم & $\begin{array}{l}12.1 \\
1 \\
\end{array}$ & $\begin{array}{l}0.073 \\
0.93\end{array}$ & $\begin{array}{l}0.045 \\
0.32 \\
\end{array}$ & $\begin{array}{l}0.457 \\
2.6 \\
\end{array}$ & $\begin{array}{l}0.2 \\
0.2 \\
\end{array}$ & $\begin{array}{l}0.277 \\
0.8 \\
\end{array}$ & $\begin{array}{l}0.05 \\
0.3 \\
\end{array}$ & $\begin{array}{l}-0,028 \\
-0.12 \\
\end{array}$ & 4.65 & 73 & 57.3 & 1,84 \\
\hline معلدة التمر الإخصادي & $\begin{array}{l}1.87 \\
0.38\end{array}$ & $\begin{array}{l}-0.013 \\
-0.2\end{array}$ & $\begin{array}{l}-0.77 \\
-1.82\end{array}$ & $\begin{array}{l}-0.14 \\
-2.83\end{array}$ & $\begin{array}{l}0.516 \\
1.77\end{array}$ & $\begin{array}{l}0.11 \\
6 \\
0.13 \\
\end{array}$ & $\begin{array}{l}0.3 \\
0.9\end{array}$ & $\begin{array}{l}0.07 \\
1.05\end{array}$ & 5.01 & 74,5 & 60 & 2.2 \\
\hline معلثة حسب رداس المل & $\begin{array}{r}-3.5 \\
4.8 \\
\end{array}$ & $\begin{array}{l}0.06 \\
1.86 \\
\end{array}$ & $\begin{array}{r}-0.06 \\
-0.28 \\
\end{array}$ & $\begin{array}{l}0.2 \\
0.6 \\
\end{array}$ & $\begin{array}{l}0.1 \\
0.33 \\
\end{array}$ & $\begin{array}{l}0.011 \\
0.38 \\
\end{array}$ & & & 2.24 & 37.7 & 15.5 & 1.22 \\
\hline \multicolumn{13}{|c|}{ 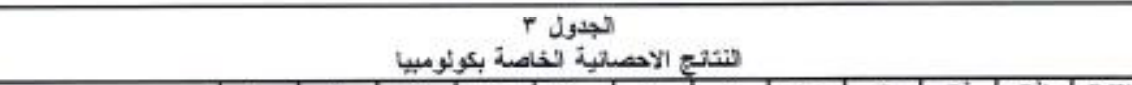 } \\
\hline & $b_{3}$ & $b_{1}$ & $b_{2}$ & $b_{5}$ & $b_{4}$ & $b_{s}$ & $b_{6}$ & $b_{7}$ & $F$ & $\mathbf{R}^{i}$ & $\left.R^{2}\right)$ & D.W \\
\hline معايلة التضشف & $\begin{array}{l}21.0 \\
1.86 \\
\end{array}$ & \begin{tabular}{|l|}
0.001 \\
1.1 \\
\end{tabular} & $\begin{array}{c}-0.037 \\
-1.1 \\
\end{array}$ & \begin{tabular}{|l|l|}
0.273 \\
1.77 \\
\end{tabular} & \begin{tabular}{|l|}
-0.22 \\
-0.52 \\
\end{tabular} & $\begin{array}{l}-0.101 \\
-0.35 \\
\end{array}$ & \begin{tabular}{|l|}
0.03 \\
0.5 \\
\end{tabular} & $\begin{array}{l}0.174 \\
1.01 \\
\end{array}$ & 3.5 & 65.6 & 42.4 & 2.32 \\
\hline 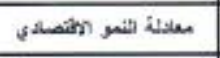 & $\begin{array}{r}-6.56 \\
-1.48 \\
\end{array}$ & $\begin{array}{c}-0.001 \\
-0.01 \\
\end{array}$ & $\begin{array}{c}-0.3 \\
-223 \\
\end{array}$ & $\begin{array}{l}0.015 \\
0.22 \\
\end{array}$ & $\begin{array}{l}0.33 \\
1.77 \\
\end{array}$ & $\begin{array}{l}0,086 \\
0.81 \\
\end{array}$ & $\begin{array}{l}0.006 \\
0.37 \\
\end{array}$ & $\begin{array}{l}0.83 \\
1.21 \\
\end{array}$ & 3.2 & 62.2 & 41.5 & 1.38 \\
\hline معلة حسب رالم فل & $\begin{array}{l}4.82 \\
0.78 \\
\end{array}$ & $\begin{array}{c}-0.047 \\
-0.42 \\
\end{array}$ & $\begin{array}{l}0.002 \\
0.14 \\
\end{array}$ & $\begin{array}{l}0.44 \\
1.78 \\
\end{array}$ & \begin{tabular}{|l|}
-0.24 \\
-2.15 \\
\end{tabular} & $\begin{array}{l}0.03 \\
1.68 \\
\end{array}$ & & & 1.92 & 54.5 & 40.2 & 1.93 \\
\hline \multicolumn{13}{|c|}{ 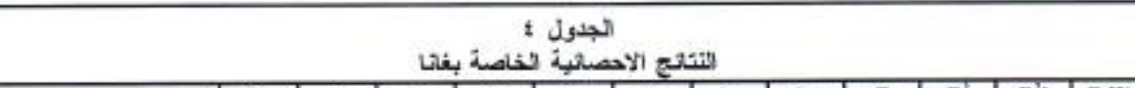 } \\
\hline & $b_{4}$ & $\mathrm{~B}_{1}$ & $\mathrm{~b}_{2}$ & $b_{3}$ & $b_{4}$ & by & $\mathrm{b}_{\mathrm{i}}$ & $\mathrm{b}_{4}$ & $F$ & $R^{1}$ & $R^{2} j$ & D.w \\
\hline معائة صضفم & $\begin{array}{l}-15.2 \\
-1.06 \\
\end{array}$ & $\begin{array}{l}0.01 \\
0.5 \\
\end{array}$ & $\begin{array}{l}0.135 \\
1.77 \\
\end{array}$ & $\begin{array}{l}0.545 \\
2.92 \\
\end{array}$ & $\begin{array}{l}-0.293 \\
-0.5\end{array}$ & $\begin{array}{l}0.152 . \\
1.77 \\
\end{array}$ & $\begin{array}{ll}0.032 \\
0.9 \\
\end{array}$ & $\begin{array}{l}0.35 \\
1.98 \\
\end{array}$ & 2.85 & 50.4 & 37.5 & 1.85 \\
\hline معلية لفو المأصساكي & $\begin{array}{l}1.64 \\
0.65 \\
\end{array}$ & \begin{tabular}{|l|}
-0.143 \\
-2.83 \\
\end{tabular} & $\begin{array}{l}0.27 \\
1.78 \\
\end{array}$ & \begin{tabular}{|l|}
0.123 \\
3.04 \\
\end{tabular} & \begin{tabular}{|l|}
-0.06 \\
-1.62 \\
\end{tabular} & $\begin{array}{r}-0.6 \\
-3.8 \\
\end{array}$ & $\begin{array}{l}0.017 \\
1.01 \\
\end{array}$ & $\begin{array}{l}0.107 \\
2.93 \\
\end{array}$ & 7,41 & 81.2 & 70.2 & 1.38 \\
\hline معثلة حسب زأمن المال & $\begin{array}{l}17.3 \\
-2.19 \\
\end{array}$ & $\begin{array}{l}-2.95 \\
-095 \\
\end{array}$ & $\begin{array}{l}0.007 \\
0.9 \\
\end{array}$ & $\begin{array}{c}-0,013 \\
-0.16 \\
\end{array}$ & \begin{tabular}{|l}
0.014 \\
1.62 \\
\end{tabular} & $\begin{array}{l}0.03 \\
1.27 \\
\end{array}$ & & & 0.66 & 21 & 0.0 & 1.63 \\
\hline \multicolumn{13}{|c|}{ - الجدول } \\
\hline & bo & B1 & b2 & b3 & b4 & b5 & 56 & b7 & $F$ & $\mathrm{R2}$ & $R 2 j$ & D.W \\
\hline معاندة لضضفم & $\begin{array}{l}12.6 \\
2.14 \\
\end{array}$ & $\begin{array}{l}-0.121 \\
-0.92\end{array}$ & $\begin{array}{c}-0.023 \\
-3.95 \\
\end{array}$ & $\begin{array}{l}0.477 \\
3.25 \\
\end{array}$ & $\begin{array}{c}0.094 \\
0.5\end{array}$ & $\begin{array}{c}-0.215 \\
-2.01 \\
\end{array}$ & $\begin{array}{c}0.021 \\
0.1\end{array}$ & + & 9.35 & 81.2 & 72.5 & 1.96 \\
\hline معانئة لنعو المأصسادي & $\begin{array}{c}-5.6 \\
-1.43 \\
\end{array}$ & $\begin{array}{c}0.145 \\
1.44 \\
\end{array}$ & $\begin{array}{c}-0.028 \\
-1.8 \\
\end{array}$ & $\begin{array}{l}0.42 \\
4.27 \\
\end{array}$ & $\begin{array}{r}0.27 \\
-2.05 \\
\end{array}$ & $\begin{array}{l}-0.42 \\
-4.16 \\
\end{array}$ & $\begin{array}{c}0.018 \\
0.3 \\
\end{array}$ & $\begin{array}{l}0.02 \\
0.18 \\
\end{array}$ & 5,65 & 76.7 & 63.1 & 2.53 \\
\hline معلة حسب رآمن العل & $\begin{array}{l}2.6 \\
5.3 \\
\end{array}$ & $\begin{array}{l}-0.54 \\
-3.2 \\
\end{array}$ & $\begin{array}{r}-0.19 \\
-2.06 \\
\end{array}$ & $\begin{array}{c}-1.34 \\
-3.1 \\
\end{array}$ & $\begin{array}{r}0.376 \\
-2.25 \\
\end{array}$ & $\begin{array}{c}0.066 \\
-0,71 \\
-0.71\end{array}$ & & & 5,06 & 64.4 & 51.6 & 1.74 \\
\hline
\end{tabular}


الدكتور نايف وفرحان [1 [ ] ]

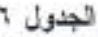

التبتج الاحصاتية الخاصة بأثريقبا الموسطى

\begin{tabular}{|c|c|c|c|c|c|c|c|c|c|c|c|c|}
\hline & $b_{4}$ & $b_{1}$ & $\mathrm{~b}_{2}$ & $b_{3}$ & $b_{4}$ & $b_{5}$ & $b_{6}$ & $b_{7}$ & $\bar{F}$ & $\mathbb{R}^{2}$ & $R^{2} j$ & D.w \\
\hline معالئ التضضخ & $\begin{array}{l}1.3 \\
-0.06\end{array}$ & * & $\begin{array}{l}0.452 \\
1.77\end{array}$ & $\begin{array}{l}0.23 \\
1.1\end{array}$ & $\begin{array}{r}-0.32 \\
-0.82 \\
\end{array}$ & $\begin{array}{r}-0.18 \\
-0.81 \\
\end{array}$ & $\begin{array}{l}-0.17 \\
-0.06\end{array}$ & $\begin{array}{l}0.051 \\
0.11\end{array}$ & 1.31 & 33.7 & 19 & 2.56 \\
\hline 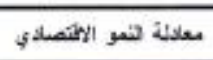 & $\begin{array}{l}-2.6 \\
-0.31\end{array}$ & $\begin{array}{l}0.026 \\
-0.26\end{array}$ & $\begin{array}{l}0.046 \\
0.43\end{array}$ & $\begin{array}{l}-0.065 \\
-0.9\end{array}$ & $\begin{array}{l}0.3 \\
.1 .03\end{array}$ & $\begin{array}{l}0.1 \\
1\end{array}$ & $\begin{array}{l}0.076 \\
0.67\end{array}$ & $\begin{array}{l}0.58 \\
3.15\end{array}$ & 2.11 & 55.1 & 29 & 2.54 \\
\hline معائة حسب رأس الصل & $\begin{array}{l}2.58 \\
1.43\end{array}$ & $\begin{array}{l}-0.014 \\
-0.6\end{array}$ & $\begin{array}{l}0.01 \\
0.7\end{array}$ & $\begin{array}{l}0.01 \\
0.33\end{array}$ & $\begin{array}{l}-0.003 \\
-0.14\end{array}$ & $\begin{array}{l}0.014 \\
0.6\end{array}$ & & & 0.55 & 15.1 & 0.0 & 1.28 \\
\hline
\end{tabular}

الجدول

الفنتقج الاحصاتية الخاصة بكينيا

\begin{tabular}{|c|c|c|c|c|c|c|c|c|c|c|c|c|}
\hline معلثئ التتضخ & $\begin{array}{l}3.71 \\
1.14 \\
\end{array}$ & $\begin{array}{c}-0.081 \\
-1.5\end{array}$ & $\begin{array}{l}0.132 \\
0.33\end{array}$ & $\begin{array}{c}0.164 \\
1.77\end{array}$ & $\begin{array}{c}0.283 \\
1.3\end{array}$ & $\begin{array}{l}-0.37 \\
-1.96 \\
\end{array}$ & $\begin{array}{l}1.25 \\
3.46\end{array}$ & $\begin{array}{c}0.014 \\
0.11\end{array}$ & 5.05 & 74.6 & 60.1 & 1.78 \\
\hline معلثلة حسو الأنصدادي & $\begin{array}{l}8.23 \\
1.54 \\
\end{array}$ & $\begin{array}{r}0.147 \\
-1.01 \\
\end{array}$ & $\begin{array}{r}-0.1 \\
-0.3 \\
\end{array}$ & $\begin{array}{l}0.083 \\
1.21 \\
\end{array}$ & $\begin{array}{l}-0.063 \\
-0.51 \\
\end{array}$ & $\begin{array}{c}0.286 \\
1.01 \\
\end{array}$ & $\begin{array}{c}0.06 \\
09 \\
\end{array}$ & $\begin{array}{l}0.01 \\
0.5 \\
\end{array}$ & 0.55 & 29.6 & 6 & 1.15 \\
\hline معائة حسب رأمن المل & $\begin{array}{l}15.9 \\
4.57 \\
\end{array}$ & $\begin{array}{l}-0.245 \\
-2.42 \\
\end{array}$ & $\begin{array}{l}-0.77 \\
-9.43 \\
\end{array}$ & $\begin{array}{r}-0.54 \\
-2.93 \\
\end{array}$ & $\cdot$ & $\begin{array}{c}0.04 \\
0.2\end{array}$ & & & 8.4 & 69.1 & 61.8 & 2.08 \\
\hline
\end{tabular}

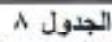

النتاتج الاحصاقية الخاصة بكوستاريكا

\begin{tabular}{|c|c|c|c|c|c|c|c|c|c|c|c|c|}
\hline & b0 & b1 & b2 & b3 & b4 & b5 & b6 & b7 & F & R2 & R2j & D.W \\
\hline & -12.5 & 0.025 & 0.45 & 0.21 & 1.64 & -0.205 & -0.732 & -0.067 & 8.02 & 82.4 & 72.1 & 2.52 \\
\hline & -0.81 & -0.6 & 0.46 & 0.24 & 6.14 & -0.82 & -1.16 & -0.08 & & \\
\hline & 11.5 & -0.08 & -0.133 & -0.085 & -0.1 & -0.045 & 0.203 & 0.015 & 0.96 & 13.2 & 0.0 & 1.9 \\
\hline & 1.34 & -0.01 & -0.28 & -0.18 & -0.47 & -0.4 & 0.58 & 0.03 & 0.96 & & & \\
\hline
\end{tabular}

الجدول 4

النتانتج الاحصائية الخاصة بالكالعيزون

\begin{tabular}{|c|c|c|c|c|c|c|c|c|c|c|c|c|}
\hline & b0 & b1 & b2 & b3 & B4 & b5 & b6 & b7 & F & R2 & R2.j & D.w \\
\hline \multirow{2}{*}{. } & 6.24 & -0.95 & -0.08 & -0.087 & 0.686 & 0.135 & -0.177 & -0.0411 & 7.15 & 79.4 & 69 & 2.13 \\
\hline & 2.17 & -0.86 & -0.7 & -1.06 & 4 & 0.76 & -1.78 & -0.5 & 7.15 & & \\
\hline
\end{tabular}

\section{1. لجذول}

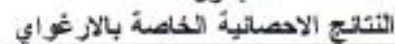

\begin{tabular}{|c|c|c|c|c|c|c|c|c|c|c|c|c|}
\hline & bo & b1 & $b_{2}$ & b3 & b4 & b5 & B6 & b7 & F & $\mathbf{R} 2$ & $\mathrm{R} 2 \mathrm{j}$ & D.w \\
\hline معلثئ التضضخ & $\begin{array}{c}-36 \\
-2.36\end{array}$ & $\begin{array}{r}-0.03 \\
-1.88\end{array}$ & $\begin{array}{l}-0.82 \\
-1.48\end{array}$ & $\begin{array}{c}0.026 \\
0.21\end{array}$ & $\begin{array}{l}1.81 \\
3.98\end{array}$ & $\begin{array}{l}2.88 \\
1.85\end{array}$ & $\begin{array}{c}0.344 \\
3,45\end{array}$ & $\begin{array}{l}0.34 \\
3.54\end{array}$ & 40.2 & 94.4 & 92.5 & 2.29 \\
\hline معانلة التمو الأتصاكاءي & $\begin{array}{l}26.8 \\
3,75\end{array}$ & $\begin{array}{l}0.25 \\
3.92\end{array}$ & $\begin{array}{l}-0.58 \\
-3.65\end{array}$ & $\begin{array}{c}-0.1 \\
-1,99\end{array}$ & $\begin{array}{l}-1.22 \\
-3.9\end{array}$ & . & $\begin{array}{l}0.104 \\
-2.14\end{array}$ & - & 8.75 & 372 & 639 & 1.73 \\
\hline معثلن هسب رنم المد & $\begin{array}{l}9.2 \\
0.65\end{array}$ & $\begin{array}{l}0.02 \\
0.22\end{array}$ & $\begin{array}{l}0.11 \\
0.43\end{array}$ & $\begin{array}{l}0.02 \\
0.02\end{array}$ & $\begin{array}{l}0.06 \\
0.07\end{array}$ & $\begin{array}{r}-0.15 \\
-0.14\end{array}$ & & & 0.1 & 3.4 & 0.0 & 22 \\
\hline
\end{tabular}




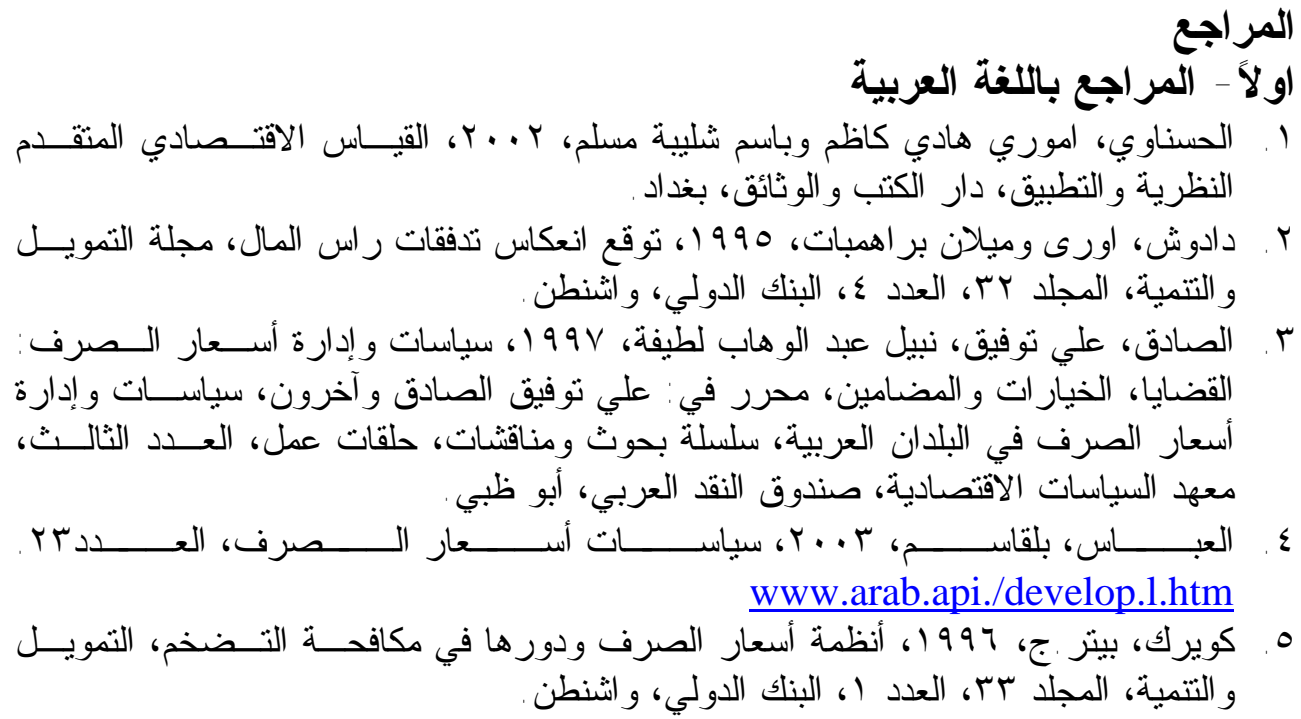

ثانياً - المراجع باللغة الاجنبية

1. David Felix ,2003, the Past s Future? The Contribution of Financial Globalization to the Current Crisis of Neo- Liberalism as A development Strategy, Working Papers Series, No:69, www.sitersources. worldbank.org/ICP/int.

2. Fahrettin Yagci ,2001,: Choice of Exchange Rate Regimes for Developing Countries, Africa Ragion Working Papers Series, No:16, www.world bank.org/afr/wps/indexs.htm .

3. IMF ,2003, International Financial Statistics, Washington CD-Rom.

4. Max Gillman, Mark Harris \& La'szlo Matyas ,2004, Inflation \& Growth: some Theory \& Evidence, www.econpapers.repec.org./cpd/zooz/42.

5. Reuren Gilck \& Micheal Hutchison ,2002, Capital Controls \& Exchange Rate Instability in Developing Economics, working papers, No: PB 00-05, Center of Pacific Asian Monetary \& Economic Studies Fedral Reseve Bank of san - Francisco, www.econ.com . www.swope.hhs.se/lunepnp/papers/Lunewp/. 2000-004.

6. World bank, 2003, World Development Indicators, Washington, CD-Rom.

7.Ziya Onis \& Suleyman Ozmucur ,1990, Exchange Rates, Inflation \& Money Supply in Turkey: Testing The Vicoins Circle Hypothesis, Journal of Economics, Vol: 32, No:4, Holland. 